\title{
Artigo Original / Original Paper \\ O gênero Chamaecrista (Leguminosae: Caesalpinioideae) no Parque Estadual do Rio Preto, São Gonçalo do Rio Preto, Minas Gerais, Brasil
}

The genus Chamaecrista (Leguminosae: Caesalpinioideae) in Parque Estadual do Rio Preto, São Gonçalo do Rio Preto, Minas Gerais, Brazil

\author{
Laís Couto Zeferino ${ }^{1,7}$, Rubens Teixeira de Queiroz ${ }^{2}$, Juliana Gastaldello Rando ${ }^{3}$, Matheus Martins T. Cota ${ }^{4}$, \\ Isabella Fernandes Fantini ${ }^{1}$, Ana Paula de Souza Caetano ${ }^{5}$ \& Ana Paula Fortuna Perez ${ }^{6,7}$
}

\begin{abstract}
Resumo
O gênero Chamaecrista possui distribuição pantropical e está bem representado na flora brasileira, principalmente em campos rupestres e matas ciliares. No Brasil são encontradas 256 espécies, sendo que 149 delas aparecem somente em Minas Gerais, o que corresponde mais da metade da diversidade do gênero no país. A área selecionada para o estudo, o Parque Estadual do Rio Preto (PERP), pertence à Cadeia do Espinhaço. A vegetação é composta principalmente por fitofisionomias de Cerrado e Campo rupestre existindo também áreas de matas ciliares e de galerias. O estudo em questão teve como objetivo realizar o levantamento florístico e um estudo taxonômico de Chamaecrista no PERP, abrangendo chave de identificação das espécies e descrições taxonômicas das mesmas. As coletas foram realizadas dentro de um período de dois anos, por meio de caminhadas assistemáticas. O material coletado foi identificado e depositado na coleção do Herbário OUPR. Foram coletados e descritos 19 táxons que compreendem às seções Absus, Chamaecrista e Xerocalyx. Palavras-chave: Cadeia do Espinhaço, campos rupestres, Cerrado, Fabaceae, PERP.
\end{abstract}

\begin{abstract}
The genus Chamaecrista has a pantropical distribution and it is well represented in the Brazilian flora, mainly in "campos rupestres" and Riparian forests. In Brazil, 256 species are found, of which 149 are found only in Minas Gerais, corresponding more than a half of genus diversity in the country. The area selected for the study, Parque Estadual do Rio Preto (PERP), belongs to Espinhaço Range. The vegetation is composed mainly of physiognomies of cerrado and "campos rupestres", also existing areas of gallery forests and galleries. The objective of this study was to carry out the floristic and taxonomic survey of Chamaecrista at PERP, to elaborate key of identification of the species and taxonomic descriptions of the same ones. The collections were carried out within a period of two years, through unsystematic walks. The collected material was identified and deposited in the OUPR and BOTU Herbaria. 19 taxa were collected and described that comprises the Absus, Chamaecrista and Xerocalyx sections.
\end{abstract}

Key words: Espinhaço Range, “campos rupestres”, Cerrado, Fabaceae, PERP.

\footnotetext{
${ }^{1}$ Universidade Federal de Ouro Preto, Inst. Ciências Exatas e Biológicas, Depto. Biodiversidade, Evolução e Meio Ambiente, Campus Universitário Morro do Cruzeiro, 35400-000, Ouro Preto, MG, Brasil.

${ }^{2}$ Universidade Federal da Paraíba, Depto. Sistemática e Ecologia - Campos I, Centro de Ciências Exatas e da Natureza, Cidade Universitária, 58051-900, João Pessoa, PB, Brasil.

${ }^{3}$ Universidade Federal do Oeste da Bahia, Prog. Pós-graduação em Ciências Ambientais, R. Prof. José Seabra Lemos 316, Recanto dos Pássaros, 47808-021, Barreiras, BA, Brasil.

${ }^{4}$ Universidade Estadual de Feira de Santana, Prog. Pós-graduação em Botânica, Av. Transnordestina s/n, Novo Horizonte, 44036-900, Feira de Santana, BA, Brasil.

${ }^{5}$ Universidade Federal de Mato Grosso, Depto. Botânica e Ecologia, Inst. Biociências, Av. Fernando Corrêa da Costa 2367, Boa Esperança, 78060-900, Cuiabá, MT, Brasil.

${ }^{6}$ Universidade Estadual Paulista, Prog. Pós-graduação em Ciências Biológicas (Botânica), IBB, Depto. Botânica, R. Prof. Dr. Antonio Celso Wagner Zanin s/n, 18618-689, São Paulo, SP, Brasil.

${ }^{7}$ Autores para correspondência: bio.fortuna@gmail.com; czlais@gmail.com
} 


\section{Introdução}

Leguminosae Juss. é a terceira maior família de Angiospermas, com 750 gêneros e 19.500 espécies (LPWG 2013), e a segunda em importância econômica no mundo, sendo superada apenas por Poaceae (Lewis et al. 2005). Atualmente, Leguminosae está compreendida por seis subfamílias e em Caesalpinioideae foi subordinada a antiga Mimosoideae, como clado Mimosoida (LPWG 2017). Segundo a nova classificação para a família, Caesalpinioideae possui 148 gêneros e cerca de 4.400 espécies (LPWG 2017).

Dentre os gêneros desta subfamília, Chamaecrista destaca-se por apresentar cerca de 330 espécies com distribuição pantropical (Irwin \& Barneby 1981), sendo as regiões Sudeste e CentroOeste do Brasil os centros de diversidade com aproximadamente 232 espécies (Irwin \& Barneby 1982; Conceição et al. 2003; BFG 2015). O gênero está inserido na tribo Cassiieae, subtribo Cassiinae, (Irwin \& Barneby 1982; Herendeen 2000; Lewis et al. 2005), e é constituído por seis seções $A b s u s$ (DC. ex Collad.) H.S. Irwin \& Barneby, Apoucouita (Benth.) H.S.Irwin \& Barneby, Caliciopsis H.S.Irwin \& Barneby, Chamaecrista, Grimaldia (Schrank) H.S. Irwin \& Barneby e Xerocalyx (Benth.) H.S. Irwin \& Barneby (Irwin \& Barneby 1982).

Recentemente, diversos trabalhos florísticos e estudos taxonômicos foram realizados no Brasil com Chamaecrista, como os de Conceição (2000) na Bahia; Dantas \& Silva (2013) e Souza \& Silva (2015) em Goiás; Scalon (2003) no Distrito Federal; Hervencio (1999), Rando (2009) e Rando et al. (2013) em Minas Gerais; Queiroz \& Loiola (2009) no Rio Grande do Norte; Camargo \& Miotto (2004) e Rodrigues et al. (2005) no Rio Grande do Sul. Aqueles realizados em Minas Gerais, Goiás e Bahia revelaram novas espécies à ciência. Segundo Brazil Flora Group (BFG 2015), atualmente no Brasil são encontradas aproximadamente 256 espécies, das quais 207 são endêmicas. De acordo com Souza \& Bertoluzzi (2012), Minas Gerais possui 149 espécies, sendo considerado o estado com maior diversidade em número de espécies do país.

O Parque Estadual do Rio Preto está incluído na Cadeia do Espinhaço, declarada Reserva da Biosfera pela UNESCO (2018) $(<\mathrm{http}: / /$ whc. unesco.org/>). A vegetação do Parque é composta principalmente por fitofisionomias de Cerrado e Campo rupestre existindo também áreas cobertas por capões de matas ciliares e de galerias (Versieux 2010).

Os solos na Cadeia do Espinhaço são arenosos, pobres em nutrientes e rasos. Mas em alguns fundos de vale, há acúmulo de sedimentos e resíduos de matéria orgânica aliados à maior umidade desses baixios, permitindo a instalação de matas exuberantes (Neves et al. 2005). Predomina a existência de quartzitos, contendo fraturas, falhas e dobramentos. As formas de relevo resultantes da dissecação fluvial são representadas pelas cristas, escarpas escalonadas e vales encaixados, adaptados às direções tectônicas (Neves et al. 2005).

Visando contribuir com o conhecimento da diversidade de Leguminosae no Parque Estadual do Rio Preto, o presente estudo teve por objetivo o levantamento e o estudo taxonômico do gênero Chamaecrista nessa unidade de conservação. Para tanto, foram realizadas descrições e comentários taxonômicos, registros fotográficos e chave para a identificação dos táxons.

\section{Material e Métodos}

O Parque Estadual do Rio Preto (PERP) está situado no município de São Gonçalo do Rio Preto em Minas Gerais e inserido no setor meridional do Complexo da Cadeia do Espinhaço, na Bacia do Rio Jequitinhonha, abrangendo uma área total de 10.755 ha (IEF $2014<$ http:www.ief.mg.gov.br $>$ ) (Fig. 1). A vegetação é composta, principalmente, por fisionomias campestres (sobretudo por Campos rupestres), assim como por capões de mata, incluindo as matas ciliares e de galeria.

As expedições para coleta do material específico de Chamaecrista no PERP foram realizadas mensalmente em um período de dois anos, aproximadamente, de janeiro de 2012 a setembro de 2014. Foram observadas as populações in situ e somente coletadas espécimes em estágio reprodutivo. $\mathrm{O}$ material amostrado foi levado às dependências do Laboratório de Morfologia e Sistemática Vegetal da Universidade Federal de Ouro Preto, onde foi herborizado e identificado. Todo o material coletado foi depositado nos Herbários "Professor José Badini" (OUPR) e "Irina Delanova Gemtchujnicov" (BOTU).

A identificação do material foi realizada com o auxílio de literatura especializada (Irwin \& Barneby 1978, 1982), por meio de comparação com espécimes depositadas no Herbário OUPR e análise de exemplares tipos disponíveis nos sítios dos herbários do The New York Botanical Garden $(<$ www.nybg.org $>$ ) e do Kew Herbarium Catalogue 
(<www.kew.org/herbcat>), além de consulta aos especialistas.

A descrição das espécies foi realizada por meio das análises morfológicas dos exemplares coletados apenas na área de estudo e, quando pertinente, foi complementada com a literatura específica do grupo (Irwin \& Barneby 1978, 1982).
A chave de identificação das espécies foi feita a partir das espécies coletadas no PERP. Os táxons apresentados no tratamento taxonômico seguem a ordem alfabética dos nomes das espécies. No tratamento taxonômico, o nome das espécies, os nomes dos autores e o padrão para a citação das obras princeps segue o Botanicum Periodicum

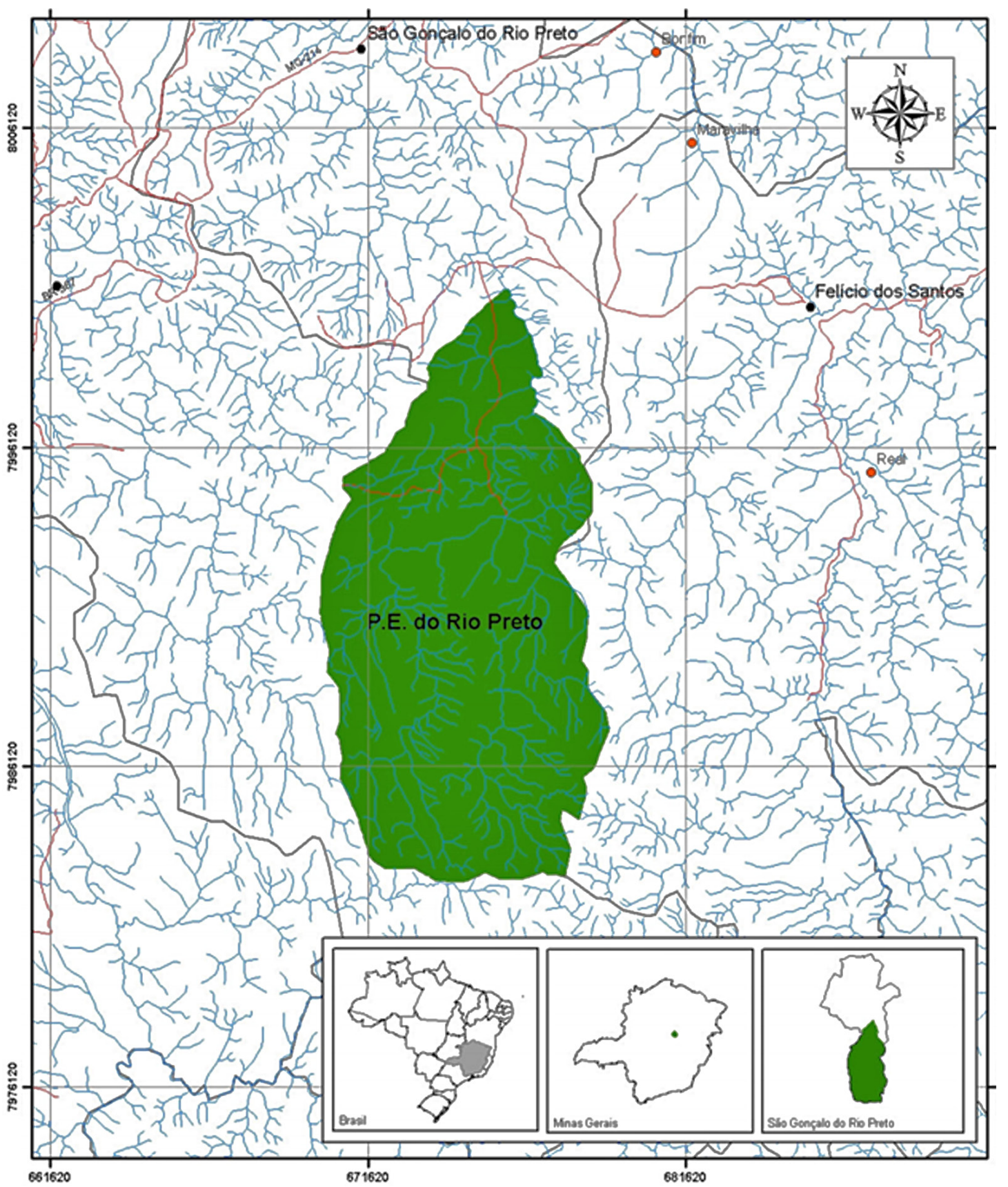

Figura 1 - Localização do Parque Estadual do Rio Preto. Fonte: IEF.

Figura 1 - Parque Estadual do Rio Preto location. Source: IEF. 
Huntianum consultado no site The International Plant Names Index (<wWw.ipni.org $>$ ) (IPNI 2012).

\section{Resultados e Discussão}

No Parque Estadual do Rio Preto foram encontradas 19 espécies do gênero Chamaecrista (Figs. 2-7) pertencentes a três seções: Absus (DC. ex Collad.) H.S. Irwin \& Barneby, Chamaecrista Moench e Xerocalyx (Benth.) H.S. Irwin \& Barneby.

Chamaecrista Moench., Meth. P1. Hort. Bot. Marburg. 272. 1794.

Arbustos ou subarbustos; ramos glabros ou cobertos por tricomas glandulares e/ou tectores. Estípulas estreito-triangulares a ovadas, caducas ou permanentes. Folhas paripinadas; folíolos em 1-55 pares, elípticos, lanceolados, oblongos, obovados, oboval-oblongos, ovados, ovaloblongos, geralmente base assimétrica, venação broquidódroma, pinada ou paralela. Inflorescência axilar, terminal, racemosa ou corimbiforme, 1-53 flores, brácteas caducas ou não. Flores pediceladas, diclamídeas, assimétricas, bissexuadas; cálice dialissépalo, sépalas elípticas, lanceoladas, ovadas, normalmente com tricomas glandulares e tectores externamente e glabras internamente; corola dialipétala, pétalas 5 , elípticas, oblongas, obovadas, ovadas, amarelas, externas geralmente 4, oblongas, interna assimétrica ou falciforme 1; androceu dialistêmone, homodínamo, estames glabros, 10; gineceu simples, ovário súpero, estipitado. Fruto legume linear, oblongo, plano-compresso, coriáceo, castanho quando maduro e verde quando imaturo, valvas retorcidas.

\section{Chave de identificação para os táxons de Chamaecrista do Parque Estadual do Rio Preto}

1. Nectário extrafloral presente no pecíolo.

2. Folha bifoliolada

..6. Chamaecrista decora

2'. Folha tetra-plurifoliolada.

3. Folhas com 2(-3) pares de folíolos.

4. Folhas (2-)3 pares, folíolos oblongos ou elípticos, ápice mucronado, pedicelo 7-14 mm compr. 15. Chamaecrista rotundata var. interstes

4'. Folha 2 pares, folíolos obovados, ápice arredondado, pedicelo 15-23 mm compr. 14. Chamaecrista ramosa var. erythrocalyx

3'. Folhas com 5 ou mais pares de folíolos.

5. Inflorescência racemosa, terminal

5. Chamaecrista debilis

5'. Inflorescência cimeira, pleiocásio, axilar ou supraxilar.

6. Inflorescência supraxilar ............ 12. Chamaecrista nictitans subsp. brachypoda

6'. Inflorescência axilar.

7. Ramos cilíndricos, 7-14 pares de folíolos, estípulas triangulares 13. Chamaecrista olesiphylla

7'. Ramos costados, 20-55 pares de folíolos, estípulas lanceoladas a ovais

8. Chamaecrista flexuosa

1'. Nectário extrafloral ausente no pecíolo.

8. Folhas caducas na antese

2. Chamaecrista basifolia

8'. Folhas persistentes na antese.

9. Folha 1 par de folíolos.

10. Estípula estreito triangular, folha séssil

10. Chamaecrista monticola

10’. Estípula ovada, lanceolada, folha peciolada 16. Chamaecrista rotundifolia

9'. Folha com 2 ou mais pares de folíolos.

11. Folha com até 4 pares de folíolos.

12. Ramos e folhas glabros, folíolo obovado, base aguda .. 4. Chamaecrista conferta

12'. Ramos e folhas com tricomas, folíolo lanceolado, oval-oblongo, elíptico, base subcordada ou assimétrica.

13. Folíolos lanceolados, ápice atenuado 18. Chamaecrista stillifera

13'. Folíolos elípticos ou oval-oblongos, ápice arredondado, emarginado ou retuso. 
14. Ramos com tricoma híspido, glandular e estrelado, folíolo oval-oblongo

17. Chamaecrista setosa var. paucivenia

14'. Ramos glabrescentes com tricoma glandular esparso, folíolo elíptico 9. Chamaecrista hedysaroides

11'. Folha com 5 ou mais pares de folíolos.

15. Inflorescência cimosa, uniflora

3. Chamaecrista cathartica

15'. Inflorescência pleiocásio, paniculada ou racemosa, com mais de uma flor.

16. Inflorescência racemosa, corimbiforme, ovário estrigoso.

11. Chamaecrista neesiana

16'. Inflorescência pleiocásio, racemo laxo, ovário tomentoso ou piloso.

17. Folha com 10-28 pares de folíolos

7. Chamaecrista filicifolia

17'. Folha com 5-7 pares de folíolos 18

18. Pecíolo $2-3 \mathrm{~mm}$ compr.. 1. Chamaecrista astrochiton

18'. Pecíolo 12-21 mm compr. 19. Chamaecrista ursina

\section{Descrições das espécies do gênero}

1. Chamaecrista astrochiton (H.S.Irwin \& Barneby) H.S.Irwin \& Barneby, Mem. New York Bot. Gard. 35: 650. 1982.

Fig. 2a

Arbusto até 1,50 m alt., ramos densamente pubescentes com tricomas glandulares e tectores. Estípulas triangular-lineares, 2-4 $\mathrm{mm}$ compr., pubescentes. Pecíolo 2-3 $\mathrm{mm}$ compr.; nectário extraforal ausente; folíolos 5-7 pares, ovados, superfície superior e inferior pubescente com tricomas glandulares e tectores, ápice atenuado, base assimétrica, 26-49 × 18-36 mm, margem repanda, ciliada, venação cladódroma. Inflorescência pleiocásio, 11-25 flores; botões florais ovóides; pedicelo 9-15 mm compr.; bractéola $1 \mathrm{~mm}$; sépalas elípticas a lanceoladas, 8-11 mm compr., glabras internamente, com tricomas na superfície externa; pétalas externas 4, obovadas, $11-14 \times 6-8 \mathrm{~mm}$; pétala interna assimétrica, cuculada, $16 \times 8 \mathrm{~mm}$; anteras pilosas 10; ovário piloso. Frutos não observados.

Material examinado: Próximo à placa de $6 \mathrm{~km}$ do restaurante F. dos Santos, $18^{\circ} 09^{\prime} 12.7^{\prime \prime}$ 'S, 43 ${ }^{\circ} 19^{\prime} 01.7^{\prime \prime} \mathrm{W}$, 7.VI.2014, fl., I.F. Fantini et al. 1 (OUPR); trilha para o Poço do Veado, $18^{\circ} 06^{\prime} 37.8^{\prime \prime}$ S, 4320'24.4”W, 8.XII.2013, f1., L.G.M. Vieira et al. 67 (OUPR).

Chamaecrista astrochiton se caracteriza por possuir a inflorescência do tipo pleiocásio. Além disso, possui pecíolo reduzido de $2-3 \mathrm{~mm}$ de comprimento. Difere da espécie mais similar, $C$. ursina, pelo tamanho do pecíolo (12-21 mm compr. em C. ursina) e formato dos folíolos (ovados em C. astrochiton e elípticos em C. ursina). Ocorre no PERP em áreas de Campo rupestre e Cerrado. Pode ser observada em fendas de afloramentos rochosos. Coletada com flores em junho e dezembro.
2. Chamaecrista basifolia (Vogel) H.S.Irwin \& Barneby, Mem. New York Bot. Gard. 35: 733. 1982.

Fig. $2 \mathrm{~b} ; 3 \mathrm{a}$

Subarbusto ereto, até $1,1 \mathrm{~m}$ alt., ramos pubescentes. Estípulas 2, cordiformes, sobrepostas ocultando os ramos; pecíolo decíduo; nectários extraflorais ausentes; folíolos unijugos, precocemente decíduos, ovados, 4-16 × 4-9 $\mathrm{mm}$, superfície superior e inferior pilosa, ápice atenuado, base cordada, margem inteira, ciliada, venação paralelódroma. Inflorescência uniflora, axilar; pedicelos 5-13 $\mathrm{mm}$ compr.; sépalas elípticas, lanceoladas, 7-9 $\mathrm{mm}$ compr., glabras na superfície interna, pubescente na superfície externa; pétalas externas 4 , obovadas, $10-11 \times$ 9-12 $\mathrm{mm}$; pétala interna possuindo a forma e o tamanho iguais as outras, $10 \times 12 \mathrm{~mm}$; anteras glabras 5, ovário lanuginoso. Legume oblongolinear, 14-41 × 3-7 mm, lanuginoso a seríceo.

Material examinado: trilha para a cachoeira Sempre Viva, 18.V.2012, fr., E.S. Cândido et al. 1040 (OUPR); trilha para o Rio Lento, $18^{\circ} 06^{\prime} 31.7^{\prime \prime} \mathrm{S}, 43^{\circ} 20^{\prime} 03.1^{\prime \prime} \mathrm{W}$, 18.XII.2013, fr., A. Soldevila et al. 23 (OUPR); trilha para a cachoeira do Crioulo próximo aos banheiros, $18^{\circ} 07^{\prime} 49.8^{\prime \prime} \mathrm{S}, 43^{\circ} 20^{\prime} 27.0^{\prime \prime} \mathrm{W}, 24 . \mathrm{III} .2014$, fl. e fr., A. Soldevila et al. 78 (OUPR); trilha para o Poço do Veado, 20²3'46.6'S, 4330'36.9'W, 26.I.2013, fr., L.C. Zeferino et al. 2 (OUPR).

Chamaecrista basifolia pertence à mesma série de C. rotundifolia (Chamaecrista sect. Chamaecrista ser. Bauhinianae) por ambas compartilharem o mesmo número de folíolos e serem as únicas espécies da seção Chamaecrista com ausência de nectários extraflorais. No entanto, são rapidamente diferenciadas pelas folhas caducas em $C$. basifolia e persistentes em C. rotundifolia, pelo hábito (ereto em C. basifolia e prostrado em $C$. rotundifolia) e formato dos 


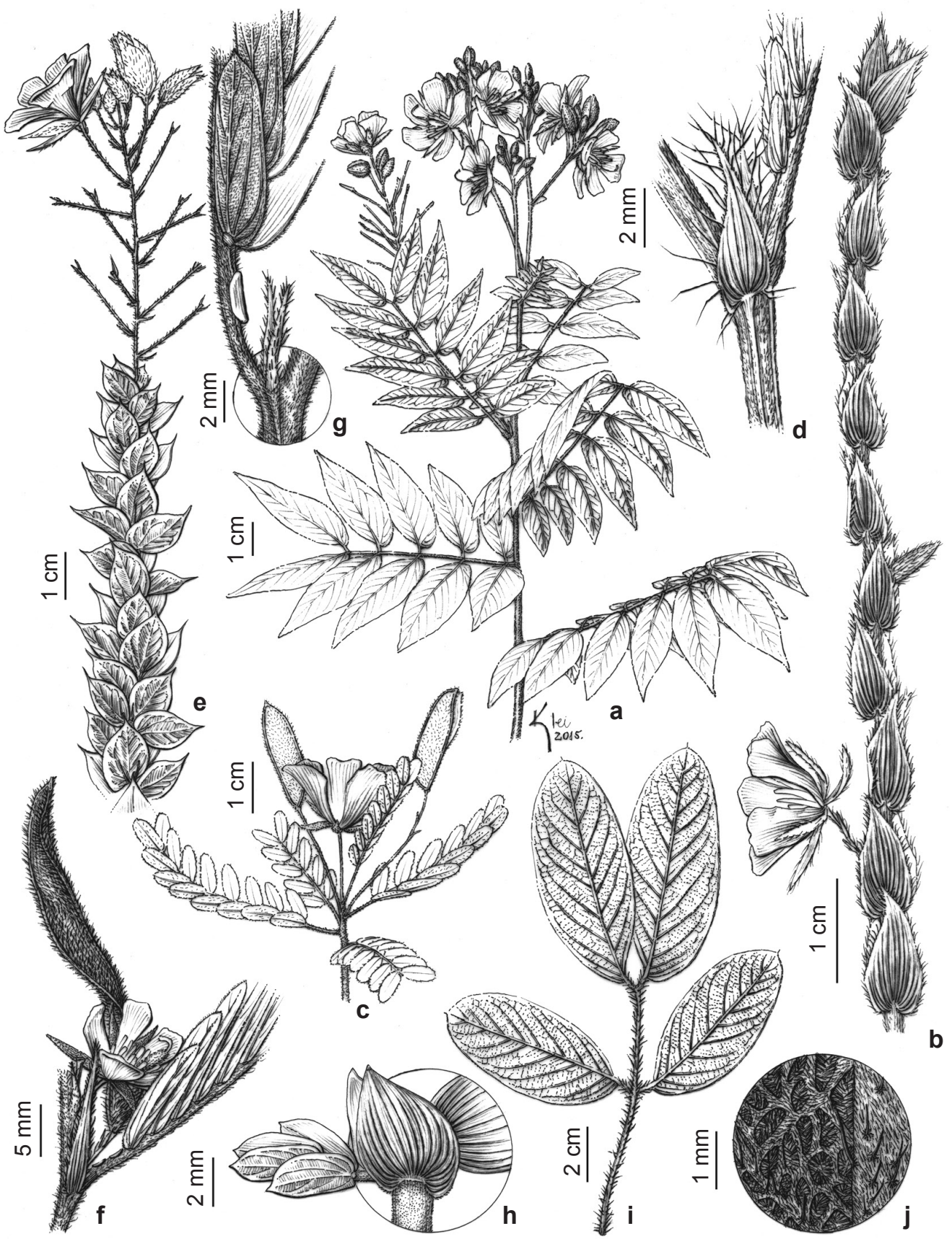

Figura 2 - a. Chamaecrista astrochiton - inflorescência pleiocásio. b. C. basifolia - ramo com folhas caducas, estípulas sobrepostas. c. C. cathartica - inflorescência uniflora, axilar. d. C. olesiphylla - estípula triangular, aguda. e. C. monticola - folíolos verticilados e sésseis. f. C. nictitans - fruto legume. g. C. filicifolia - estípula linear. h. C. flexuosa var. flexuosaestípula lanceolada a oval. i-j. C. setosa $-\mathrm{i}$. folhas com 2 pares de folíolos, opostos, oboval-oblongos; j. tricomas glandulares e tectores. (a. I.F. Fantini et al. 1; b. A. Soldevila et al. 78; c. I.F. Fantini et al. 5; d. A.P. Fortuna-Perez et al. 1480; e. A.P. Fortuna-Perez et al. 1594; f. M. Borba et al. 2; g. I.F. Fantini et al. 31; h. L.C. Zeferino et al. 29; i-j. L.G.M. Vieira et al. 28). Figure 2 - a. Chamaecrista astrochiton - pleiochasium inflorescence. b. C. basifolia - stem with caduceous leaves, overlapped stipules. c. $C$. cathartica - axilar, uniflorous inflorescence. d. C. olesiphylla - triangular, acute stipule. e. C. monticola - verticillate and sessile leaflets. f. C. nictitans - pod. g. C. filicifolia - linear stipule. h. C. flexuosa var. flexuosa - lanceolate to ovate. i-j. C. setosa - i. leaves with 2 leaflets pairs, opposite, oboval-oblong; j. glandular and tectors hairs. (a. I.F. Fantini et al. 1; b. A. Soldevila et al. 78; c. I.F. Fantini et al. 5; d. A.P. Fortuna-Perez et al. 1480; e. A.P. Fortuna-Perez et al. 1594; f. M. Borba et al. 2; g. I.F. Fantini et al. 31; h. L.C. Zeferino et al. 29; i-j. L.G.M. Vieira et al. 28). 
folíolos (ovados em C. basifolia e obovados em C. rotundifolia). Essa espécie ocorre em solos pedregosos de áreas de Cerrado e Campo rupestre quartzítico. Coletada com frutos de dezembro a maio e com flores em março.

3. Chamaecrista cathartica (Mart.) H.S. Irwin \& Barneby, Mem. New York Bort. Gard. 35: 647. 1982.

Fig. 2c; $3 b$

Subarbusto escandente até $1 \mathrm{~m}$ alt.; ramos com tricomas glandulares e tectores. Estípulas triangularlineares, 2-6 mm compr., caducas. Pecíolos 12-20 mm compr., pubescentes com tricomas glandulares e tectores; nectários extraflorais ausentes; folíolos 5-11 pares, oblongos a elípticos, ápice arredondado a agudo, mucronado, base assimétrica, 6-17 × 1-7 $\mathrm{mm}$, face adaxial esparso pubescente com presença de tricomas glandulares, face abaxial com tricomas tectores, margem inteira com tricomas glandulares e tectores, nervura broquidódroma. Inflorescência cimosa, uniflora, axilar; pedicelo 33-40 mm compr.; brácteola setiforme, 5-8 mm compr.; sépalas elípticas, 11-14 mm compr., acuminadas, externamente com tricomas, internamente glabrescente; pétalas externas 3, obovadas, 6-17 $\times$ 9-16 mm, pétala adaxial flabeliforme, $11 \times 9$ $\mathrm{mm}$, pétala interna assimétrica, $13 \times 8 \mathrm{~mm}$, falcada; anteras glabras, 10; ovário seríceo. Legume linear, 25-37 × 5-7 mm, com tricomas glandulares e tectores, coriáceo.

Material examinado: roteiro "Pinturas Rupestres", 8.XII.2013, fl. e fr., L.G.M. Vieira et al. 101 (OUPR); próximo ao mirante do Lajeado, $18^{\circ} 08^{\prime} 16.9^{\prime \prime} \mathrm{S}$, $43^{\circ} 21^{\prime} 11.0$ 'W, 27.X.2013, fl. e fr., L.C. Zeferino et al. 24 (OUPR); próximo à placa da $6 \mathrm{~km}$ do restaurante $\mathrm{F}$. do Santos, $18^{\circ} 09^{\prime} 12.7^{\prime \prime}$ S, 4319'01.7'W, 7.VI.2014, fl. e fr., I.F. Fantini et al. 5 (OUPR); próximo à casa de hóspedes depois da porteira secundária para a cachoeira Sempre Viva, $18^{\circ} 07^{\prime} 48.5^{\prime}$ 'S, 4321'31.4’W, 8.VI.2014, fl. e fr., I.F. Fantini et al. 20 (OUPR).

Chamaecrista cathartica pode ser facilmente distinguida por apresentar inflorescência axilar com tricomas glandulares e uniflora. Todas as demais espécies que possuem tricomas glandulares têm inflorescência terminal. Essa espécie é encontrada em Campos rupestres e é amplamente distribuída pelos cerrados do PERP. Coletada com flores e frutos de junho a dezembro.

4. Chamaecrista conferta (Benth.) H.S.Irwin \& Barneby, Mem. New York Bot. Gard. 35: 658.1982.

Fig. 3c-d

Subarbusto até $2,2 \mathrm{~m}$ alt., ramificado ou não; ramos glabros. Estípulas subuladas, 1,6-3,6 mm compr., persistentes. Pecíolos 3,3-7,6 mm compr.; nectários extraflorais ausentes; folíolos 2 pares, obovados, coriáceos, ápice arredondado, mucronado, base aguda, 11,9-20 × 1,15-4,6 $\mathrm{mm}$, glabros na face adaxial e abaxial, margem inteira, nervação broquidódroma. Inflorescência racemosa, corimbiforme, terminal, congesta; botões florais globosos; 26-53 flores; pedicelo 1,9-4,4 mm; sépalas elípticas, 5-7,3 mm compr., ápice arredondado a agudo, internamente glabras, externamente pubescentes; pétalas externas 4, obovadas, 9,1-11 × 5,9-7,1 mm, pétala interna oboval, assimétrica, $11 \times 4,7 \mathrm{~mm}$; anteras glabras, 10; ovário seríceo. Legume oblongo, 22,5-31,4 × 4,8-7,7 mm, glabro, coriáceo.

Material examinado: trilha depois da "Vargem da Estrela" próximo ao limite do Parque, $18^{\circ} 07^{\prime} 40.5$ "S, 4322'50.1"W, 22.VIII.2014, fl. e fr., L.C. Zeferino et al. 40 (OUPR).

Chamaecrista conferta pode ser diferenciada das demais espécies do PERP por possuir folhas com 2 pares de folíolos, obovados. Possui pecíolos pequenos de 3,3-7,6 $\mathrm{mm}$ de comprimento e apresenta inflorescência racemosa-corimbiforme, congesta. Ocorre em afloramentos rochosos de áreas de Cerrado e Campo rupestre. Coletada com flores e frutos em agosto.

5. Chamaecrista debilis (Vogel) H.S. Irwin \& Barneby, Mem. New York Bot. Gard. 35: 647. 1982.

Figs. 3e-f

Arbusto até 1,50 m alt., ramos glabros; estípulas deltoides, caducas; pecíolo 21-25 mm compr.; nectário extraforal 1, séssil; folíolos 8-19 pares, 9-12 × 3-5 mm, oblongos, glabros em ambas as faces, ápice arredondada, base assimétrica, margem inteira a repanda, venação hifódroma. Inflorescência racemosa, terminal, laxa, 2-8 flores; botões florais globosos; pedicelos 9-18 mm compr.; brácteas e bractéolas com tricomas glandulares, deltóides; sépalas elípticas, 7-10 mm compr., glabras; pétalas externas 4, elípticas 11-15 $\times 7-9 \mathrm{~mm}$; pétala interna oboval, assimétrica, $16 \times$ $10 \mathrm{~mm}$; anteras glabras, 10, ovário glabro. Legume linear, 24-37 × 5-7 mm, glabro.

Material examinado: $18^{\circ} 07^{\prime} 02.6$ "S (aprox.), 4320'51.7'W (aprox.), III.2012, fr., M. Borba et al. 23 (OUPR); Mirante da Lapa, 1805'41.6”S, 4320'33.7'W, 18.XII.2013, fl., A. Soldevila et al. 28 (OUPR); trilha da cachoeira Sempre Viva para a Forquilha, $18^{\circ} 08^{\prime} 22.2^{\prime}$ S, 43²0'41.2"W, 27.X.2013, fl., L.C. Zeferino et al. 27 (OUPR); proximidades do Mirante da Lapa, 1805'41.6”'S (aprox.), 43²0'33.7'W (aprox.), III.2012, fl., A.P. Fortuna-Perez et al. 1404 (OUPR). 

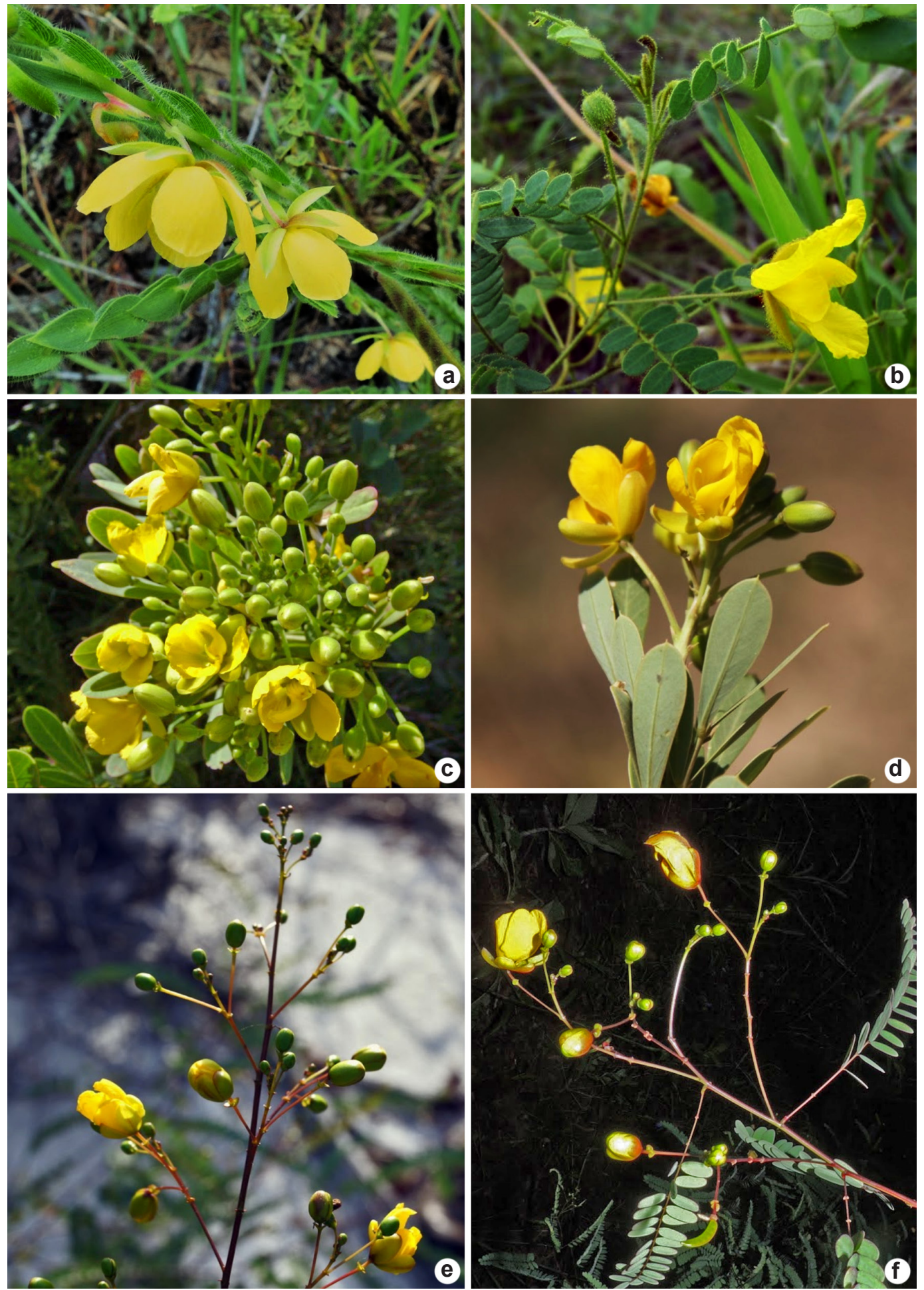

Figura 3 - a. Chamaecrista basifolia - ramo com folhas precocemente caducas, sépalas homomórficas. b. $C$. cathartica - inflorescência axilar, uniflora. c-d. C. conferta - c. inflorescência congesta; d. folíolos obovados. e-f. C. debilis - e. inflorescência terminal; f. folíolos oblongos. Fotos: Zeferino LC, Queiroz RT.

Figure 3 - a. Chamaecrista basifolia - stem with caduceous leaves, homomorphic sepals. b. C. cathartica - axilar inflorescence, uniflore. c-d. C. conferta - c. inflorescence congestous; d. obovate leaflets. e-f. C. debilis - e. terminal inflorescence; f. oblong leaflets. Photos: Zeferino LC, Queiroz RT. 
Chamaecrista debilis se difere das outras espécies ocorrentes no PERP por possuir folhas com 8-19 pares de folíolos oblongos, sendo o par basal extremamente reduzido se comparado aos outros pares. Possui nectário extrafloral séssil, localizado próximo a base do pecíolo. Ocorre no Cerrado e Campo rupestre quartzítico. Coletada com flores em março, outubro e dezembro e frutos em março.

6. Chamaecrista decora (H.S. Irwin \& Barneby) Conc., L.P. Queiroz \& G.P. Lewis, Pl. Syst. Evol. 270 (3-4): 204. 2008.

Fig. $4 \mathrm{a}$

Subarbusto até $1,50 \mathrm{~m}$ alt., ramos glabrescentes. Estípulas triangulares, até $1 \mathrm{~mm}$ compr.; pecíolo 7-15 mm compr.; nectário extraforal 1, séssil; folíolos 1 par, 26-49 × 18-36 mm, obovados a largo-elípticos, coriáceos, superfície superior lisa, superfície inferior pulverulenta, ápice arredondada, base atenuada, margem inteira, venação cladódroma. Inflorescência racemo, 1-3 flores, terminal; botões florais globosos; pedicelos 27-30 mm compr.; sépalas elípticas, lanceoladas, 9-12 mm compr., glabras internamente, com tricomas na superfície externa; pétalas externas 4, obovadas, 18-22 × 11-14 mm; pétala interna assimétrica, cuculada, $18 \times 7 \mathrm{~mm}$; anteras glabras, 10, ovário glabro. Legume linear, 52-81 × 9-13 $\mathrm{mm}$, glabro.

Material examinado: Córrego da Lapa, $18^{\circ} 05^{\prime} 13.0^{\prime \prime}$ 'S, 4319'52.7'W, 8.XII.2013, fl. e fr., L.G.M. Vieira et al. 89 (OUPR); trilha para a cachoeira do Crioulo, $18^{\circ} 08^{\prime} 44.1$ ”S, $43^{\circ} 22^{\prime} 09.8^{\prime \prime} \mathrm{W}, 24 . \mathrm{III} .2014$, fl. e fr., A. Soldevila et al. 97 (OUPR); 18 07’2.6”S (aprox.), 4320'51.7'W (aprox.), III.2012, fl., M. Borba et al. 25 (OUPR); próximo à placa "Roteiro Pinturas Rupestres", $18^{\circ} 06^{\prime} 33.2^{\prime \prime}$, $43^{\circ} 20^{\prime} 16.2^{\prime \prime} \mathrm{W}, 27 . X .2013$, fl., L.C. Zeferino et al. 28 (OUPR); trilha depois do Rio Lento, $18^{\circ} 06^{\prime} 29.0^{\prime \prime S}, 4^{\circ} 19^{\prime} 57.1^{\prime \prime} \mathrm{W}, 8 . X I I .2013$, fl., L.G.M. Vieira et al. 72 (OUPR); Vau Bravo, 18 06'30.1”'S, 4319'53.5”'W, 8.XII.2013, fl., L.G.M. Vieira et al. 74 (OUPR); Córrego do Taiobal, 1809'25.4”'S, 4319'01.9"W, 7.VI.2014, fr., I.F. Fantini et al. 10

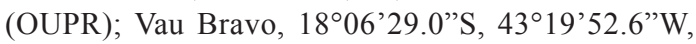
21.VIII.2014, fr., L.C. Zeferino et al. 36 (OUPR).

Chamaecrista decora pode ser identificada facilmente pelas folhas com apenas um par de folíolos obovados a largo-elípticos. Os frutos glabros, quando maduros, também são característicos dessa espécie por serem vináceos. É encontrada em abundância no PERP. Ocorre em solo rochoso e arenoso de Campo rupestre e Cerrado. Coletada com flores em março, outubro e dezembro, e frutos em março, junho, agosto e dezembro.
7. Chamaecrista filicifolia (Benth.) H.S. Irwin \& Barneby, Mem. New York Bot. Gard. 35: 655. 1982.

Fig. 4b-c

Subarbusto até $1 \mathrm{~m}$ alt., ramos densamente pubescentes com tricomas predominantemente tectores. Estípulas lineares, 2-5 mm compr., caducas; pecíolos 9-27 mm compr., pubescentes, oblíquos; nectários extraflorais ausentes; folíolos 10-28 pares, apicalmente menores, geralmente elípticos, algumas vezes suborbiculares ou ovais, ápice obtuso a emarginado, mucronado, base assimétrica, $4-15 \times 3-10 \mathrm{~mm}$, face adaxial subglabra a pubérula com tricomas tectores, face abaxial esparsamente pubescentes com tricomas glandulares e tectores, margem inteira, nervura eucamptódroma. Inflorescência racemosa, 1-2 flora, terminal, laxa; botões florais ovais a obovados, com ápice agudo, às vezes globosos com ápice apiculado; pedicelo 21-32 mm compr.; sépalas elípticas, 11-13 mm compr., acuminadas, externamente com tricomas, internamente glabrescentes; pétalas externas 4, obovadas, 15-19 $\times 12-18 \mathrm{~mm}$, pétala interna cuculada, $14 \times 5 \mathrm{~mm}$; anteras glabras, 10; ovário rufo-tomentoso. Legume oblongo, 43-45 × 5-7 mm, pubescente, coriáceo. Material examinado: 7.VI.2014, fl. e fr., I.F. Fantini et al. 31 (OUPR); próximo à placa das corredeiras, $18^{\circ} 08^{\prime} 23.7^{\prime \prime}$ 'S, 43'19'45.4”W, 7.VI.2014, fl., I.F. Fantini et al. 2 (OUPR); trilha para a cachoeira do Crioulo, 24.III.2014, fl., A. Soldevila et al. 90 (OUPR); trilha para as corredeiras depois do poço de areia, $18^{\circ} 08^{\prime} 13.7^{\prime \prime} \mathrm{S}$, 4319'53.1"W, 7.VI.2014, fl., I.F. Fantini et al. 29 (OUPR); trilha para as corredeiras depois do poço de areia, $18^{\circ} 08^{\prime} 13.7^{\prime \prime} \mathrm{S}, 43^{\circ} 19^{\prime} 53.1$ 'W, 7.VI.2014, fl., I.F.

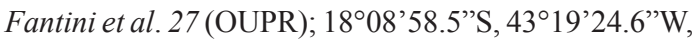
7.VI.2014, fl., I.F. Fantini et al. 3 (OUPR).

Chamaecrista filicifolia apresenta ramos com tricomas tectores. Possui folhas com 10-28 pares de folíolos sendo esses de menores dimensões quando próximos à inflorescência. É encontrada em áreas de Campo rupestre e Cerrado. Coletada com flores em março e junho e frutos em junho.

8. Chamaecrista flexuosa (L.) Grenee, Pittonia 4:27.1899. Fig. 4d-e

Subarbusto até $1 \mathrm{~m}$ alt.; ramos fractiflexos, pubescentes a glabros, flexuosos, costados. Estípulas lanceoladas a ovais, ápice agudo a acuminado, base cordada, 5-15 × 2-4 mm, persistentes; pecíolo 3-7 mm compr., pubescente; nectários extraflorais $1-2$, pateliformes, curtopedicelados; folíolos 20-55 pares, oblongos, ápice acuminado, base assimétrica, 4-9 × 1-1,5 $\mathrm{mm}$, pubescente a glabro em ambas as faces, 
margens ciliadas com tricomas longos, venação acródroma. Inflorescência axilar, uniflora; pedicelo 22-30 mm compr., pubescente; bractéolas 3,5 mm compr., triangulares; sépalas ovadas, acuminadas ou agudas, 9-10 cm compr., externamente pubescentes, internamente glabras; pétalas externas 4, ovadas, base atenuada, 13-15 × 8-10 mm; pétala interna cuculada, $14 \mathrm{~mm}$ compr.; estames 10 , anteras glabras; ovário estrigoso. Legume linear, 38-50 × 3-5 mm, plano, levemente estrigoso.
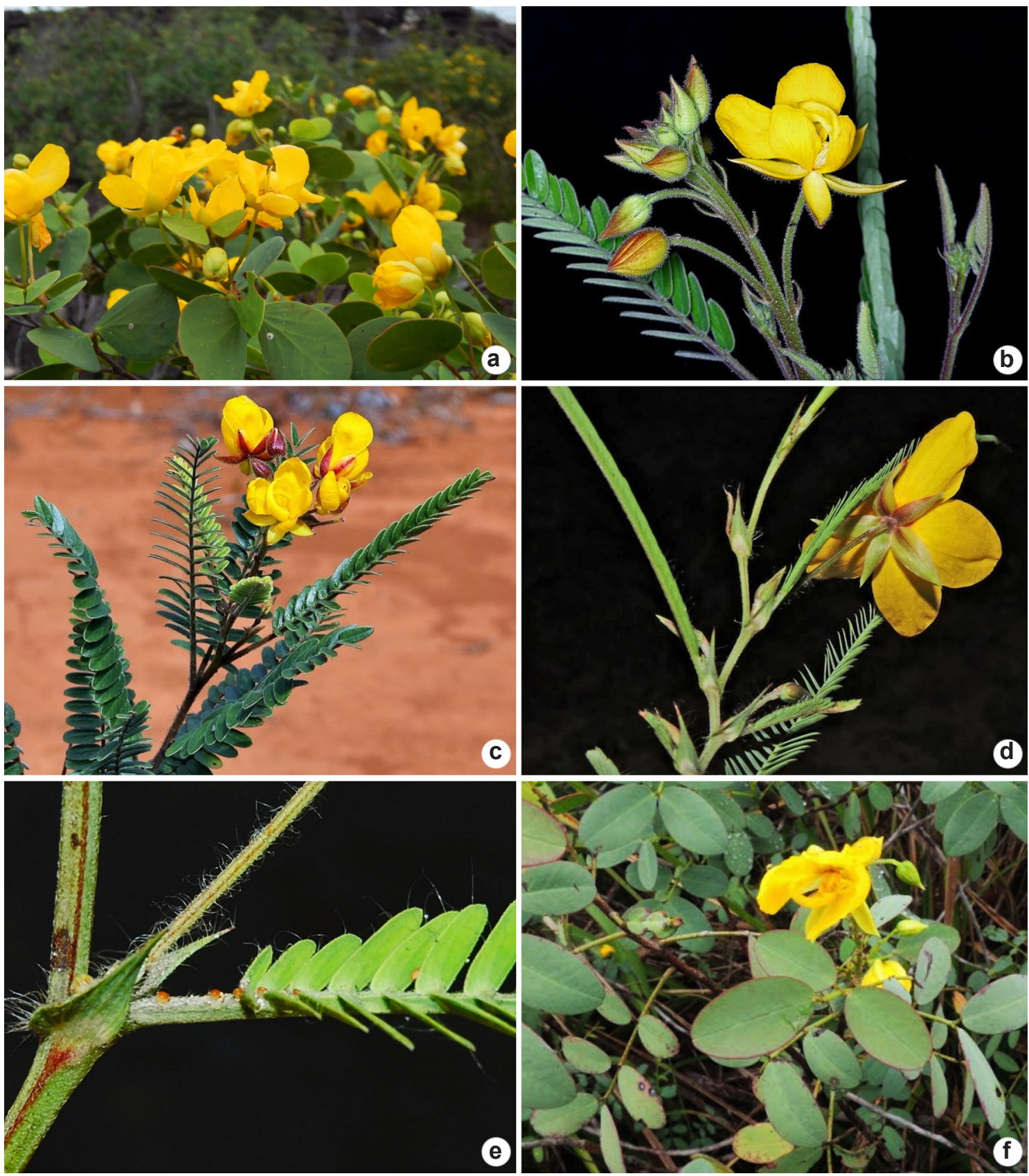

Figura 4 - a. Chamaecrista decora - folha bifoliolada. b-c. C. filicifolia - b. inflorescência; c. ramo com folha multijuga. d-e. C. flexuosa - d. ramo fractiflexo; e. nectários sésseis no pecíolo e raque. f. C. hedysaroides - folha 2-3 pares de folíolos. Fotos: Cordoba AS, Queiroz RT.

Figure 4 - a. Chamaecrista decora - bifoliolate leaf. b-c. C. filicifolia - b. inflorescence; c. branch with multijug leaf. d-e. C. flexuosa-d. fractiflexous stem; e. sessile nectaries in the petiole and rachis. f. C. hedysaroides - leaves with 2-3 leaflet pairs. (Photos: Cordoba AS, Queiroz RT. 
Material examinado: trilha entre o Vau Bravo e Vau das Éguas, $18^{\circ} 06^{\prime} 06.2^{\prime}$ 'S, 4319'45.0”W, 8.XII.2013, fl. e fr., L.G.M. Vieira et al. 86 (OUPR); 8.XII.2013, fl. e fr., L.G.M Vieira et al. 64 (OUPR); trilha próxima às pinturas rupestres, $18^{\circ} 05^{\prime} 43.1^{\prime \prime S}, 43^{\circ} 20^{\prime} 32.4$ 'W, 28.X.2013, fl. e fr., L.C. Zeferino et al. 29 (OUPR).

Chamaecrista flexuosa diferencia-se das outras espécies que ocorrem no PERP por apresentar ramos flexuosos, estípulas lanceoladas a ovais, agudas a acuminadas, e pelo número de folíolos, que varia de 20-55 pares. Esta espécie foi encontrada em áreas de Cerrado e Campo rupestre, sob solos areno-pedregosos. Coletada com flores e frutos em outubro e dezembro.

9. Chamaecrista hedysaroides (Vogel) H.S. Irwin \& Barneby, Mem. New York Bot. Gard. 35: 656. 1982.

Fig. $4 \mathrm{e}$

Subarbusto até $2 \mathrm{~m}$ alt., ramos glabrescentes com tricomas glandulares esparsos, oblíquos. Estípulas triangulares, 1-2 mm compr., caducas; pecíolos 6-17 mm compr., glabrescentes; nectários extraflorais ausentes; folíolos 2-4 pares, elípticos, coriáceos, ápice arredondado, emarginado, mucronado, base subcordada a assimétrica, 8-37 $\times$ 5-14 mm, face adaxial glabra, com tricomas glandulares esparsos na face abaxial, margem inteira, nervura broquidódroma. Inflorescência axilar, 2-12-flora, botões florais turbinados; pedicelo 14-18 mm compr.; sépalas elípticas, acuminadas, externamente com tricomas, internamente glabrescentes, 10-14 mm compr., pétalas externas 3 , obovadas, $11-15 \times 8-12 \mathrm{~mm}$, pétala adaxial ligeiramente flabeliforme, 14-9 $\mathrm{mm}$, pétala interna assimétrica, falcada, $12 \times 6$ $\mathrm{mm}$; anteras glabras; ovário indumentado. Legume oblongo, 21-30 × 6-9 mm, superfície com aspecto ceroso, presença de tricomas glandulares, coriáceo. Material examinado: alto da cachoeira do Crioulo, $18^{\circ} 08^{\prime} 48.5 \mathrm{~S}, 43^{\circ} 22^{\prime} 11.9^{\prime} \mathrm{W}, 27 . X .2013$, fl. e fr., L.C. Zeferino et al. 25 (OUPR); trilha para as Corredeiras, 1809'04"S, 4319'38.3'W, 25.III.2014, fl. e fr., $A$. Soldevila et al. 106 (OUPR); alto da cachoeira do Crioulo, $18^{\circ} 08^{\prime} 48.3^{\prime}$ 'S, 4322'10.7'W, 27.X.2013, fl., L.C. Zeferino et al. 26 (OUPR); 1807'36.8”S, 4322'47.4'W, 23.VIII.2014, fl., L.C. Zeferino et al. 53 (OUPR); 1807'36.8'S, 4322'47.4'W, 25.VIII.2014, fl., L.C. Zeferino et al. 54 (OUPR);

Chamaecrista hedysaroides é de fácil identificação por possuir folhas com 2-4 pares de folíolos elípticos e coriáceos. Essa espécie é encontrada em áreas de Campo rupestre e Cerrado, em solo pedregoso. Coletada com flores em março, agosto e outubro, e frutos em março e outubro.
10. Chamaecrista monticola (Mart. ex Benth.) H.S. Irwin \& Barneby, Mem. New York Bot. Gard. 35: 659. 1982.

Fig. 2e

Arbusto até $4 \mathrm{~m}$ alt., ramificado; ramos pubescentes com tricomas glandulares e tectores. Estípulas estreito-triangulares, 5,8-6,2 mm compr., persistentes; nectários extraflorais ausentes; folhas sésseis; folíolos 1 par, verticilados, coriáceos, elípticos a ovados, ápice levemente acuminado, mucronado, base assimétrica, 6,3-20,3 × 3,8-12,9 $\mathrm{mm}$, pubescentes em ambas as faces, margem inteira, nervura broquidódroma. Inflorescência racemosa-corimbiforme, terminal, congesta; botões florais turbinados; 3-13 flores; pedicelo com tricomas glandulares e tectores, 7,1-20,1 mm; sépalas elípticas a lanceoladas, 14,84-17,18 mm compr., internamente glabras, externamente pubescentes com tricomas glandulares e tectores; pétalas externas 4, obovadas, 15,8-20,5 × 10,7-14,8 $\mathrm{mm}$, pétala interna diferenciada, assimétrica, 17,7 $\times$ $8,8 \mathrm{~mm}$; anteras glabras 10; ovário seríceo. Legume oblongo, 19,5-29,7 × 7,3-8,9 mm, extremamente pubescente com tricomas glandulares, coriáceo.

Material examinado: Cachoeira da Sempre Viva, $18^{\circ} 08^{\prime} 32.7^{\prime}$ 'S, 4320'59.6”'W, 8.VI.2014, fl. e fr., A.P. Fortuna-Perez et al. 1594 (OUPR).

Chamaecrista monticola pode ser reconhecida pela folha séssil, pelos folíolos verticilados, ovados. Possui botões florais e cálice vináceos. Coletada em um barranco próximo as quedas de água da cachoeira "Sempre Viva" com população abundante. Coletada com flores e frutos em junho.

11. Chamaecrista neesiana (Benth.) H.S. Irwin \& Barneby, Mem. New York Bot. Gard. 35: 653. 1982.

Fig. $5 a$

Subarbusto ereto, até $2 \mathrm{~m}$ alt., pubescente; ramos pubérulos, com tricomas glandulares pistiliformes, esparsos, não flexuosos. Estípulas filiformes, 2-3 mm compr., caducas; pecíolo 10-20 mm compr., pubescente; nectários extraflorais ausentes; folíolos 5-12 pares, oblongos, algumas vezes lanceolados, ápice arredondado a cuneado, base assimétrica, 10-18 $\times 3-7 \mathrm{~mm}$, margem inteira, ciliada, pubérulos em ambas as faces, tricomas tectores presentes na face adaxial, tricomas tectores e glandulares filiformes na face abaxial, venação camptódroma. Inflorescência racemosa, corimbiforme, axial, 6-11 flores; pedicelo 20-27 mm compr., pubescente; sépalas elípticas a lanceoladas, 10-12 cm compr.; externamente pubescentes, internamente glabras; pétalas externas 4, obovadas, base atenuada, 12-13 × 6-10 mm; 

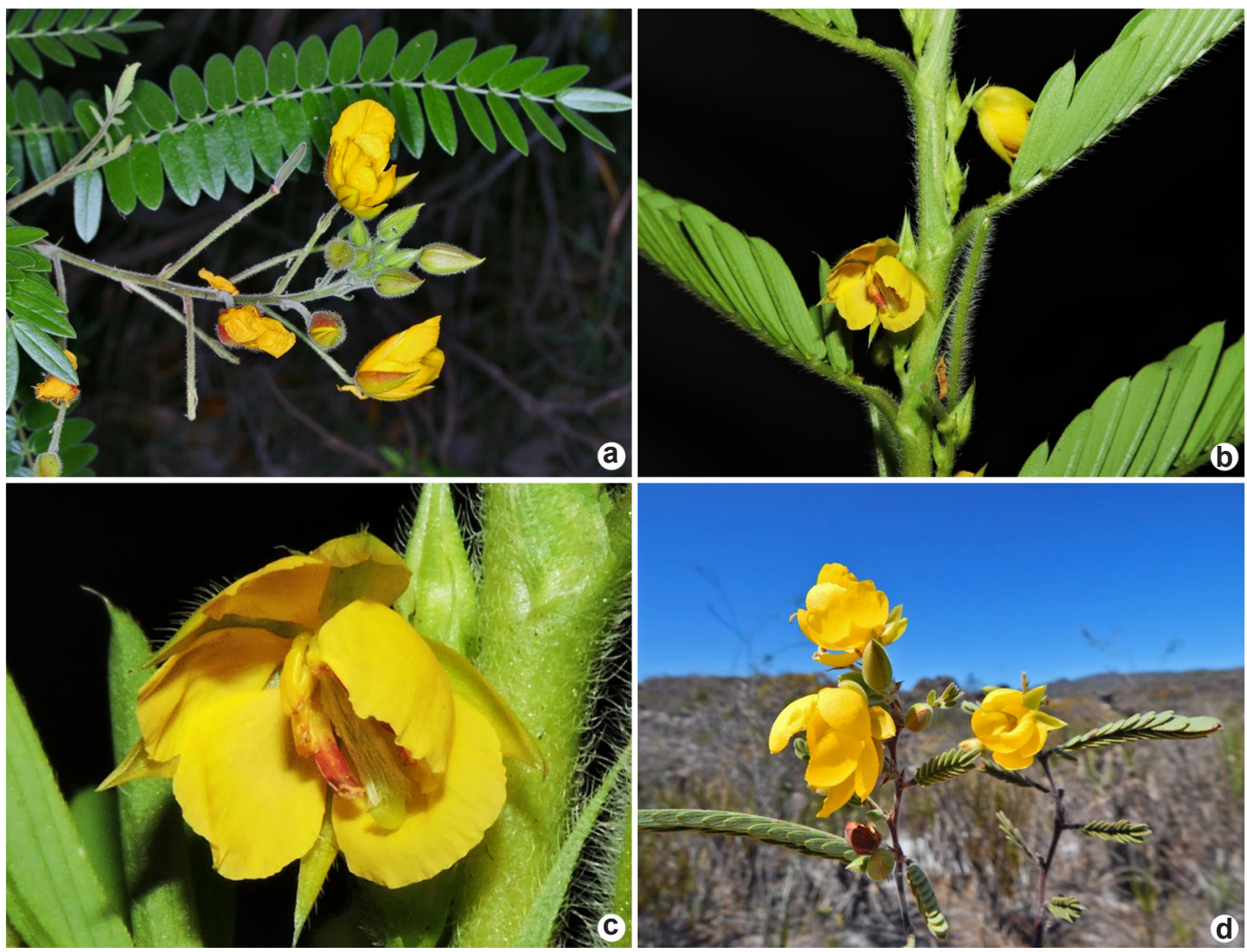

Figura 5 - a. Chamaecrista neesiana - folha multijuga, inflorescência corimbiforme. b-c. C. nictitans - b. inflorescência supraxilar; c. pétalas unguiculadas. d. C. olesiphylla-ramo fractiflexo. Fotos: Zeferino LC, Queiroz RT. Figure 5 - a. Chamaecrista neesiana - multijugue leaf, corimbiform inflorescence. b-c. C. nictitans - b. supraxilar inflorescence; c. unguiculate petals. d. C. olesiphylla - fractiflexous stem. Photos: Zeferino LC, Queiroz RT.

pétala interna cuculada, $14 \mathrm{~mm}$ compr.; anteras glabras; ovário estrigoso. Legume oblongo, 22-27 $\times$ 5-7 mm, levemente estrigoso.

Material examinado: trilha para as cachoeiras, $18^{\circ} 07^{\prime} 52.4^{\prime \prime} \mathrm{S}, 43^{\circ} 20^{\prime} 16.0^{\prime \prime} \mathrm{W}, 24 . \mathrm{III} .2014$, fl., $A$. Soldevila et al. 72 (OUPR); Vargem da Estrela, $18^{\circ} 07^{\prime} 38.9^{\prime \prime S}, 43^{\circ} 21^{\prime} 26.7^{\prime}$ 'W, 7.XII.2013, fr., L.G.M. Vieira et al. 26 (OUPR); 1806'34.6”'S (aprox.), $43^{\circ} 20^{\prime} 19.5$ "W (aprox.), III.2012, fl., A.P. FortunaPerez et al. 1411 (OUPR); trilha para as corredeiras, $18^{\circ} 08^{\prime} 11.8^{\prime \prime}$ ' $43^{\circ} 20^{\prime} 19.1$ 'W, 25.III.2014, fl. e fr., $A$. Soldevila et al. 112 (OUPR); antes da portaria do PERP, 18.V.2012, fl., E.S. Cândido et al. 1028 (OUPR).

Chamaecrista neesiana caracteriza-se por apresentar 5-12 pares de folíolos, pubérulos em ambas as faces. De acordo com Irwin \& Barneby (1977) são reconhecidas 3 variedades: C. neesiana (Benth.) H.S. Irwin \& Barneby var. neesiana, C. neesiana var. laxiracemosa (Harms) H.S. Irwin \& Barneby, C. neesiana var. subnitida (Taub.)
H.S. Irwin \& Barneby, definidas com base no comprimento dos folíolos, tipo de inflorescência e hábito. No PERP foi encontrada apenas a variedade típica. Pode ser confundida muitas vezes com $C$. cathartica, por apresentarem folíolos geralmente oblongos (às vezes elípticos em $C$. cathartica), contudo são facilmente diferenciadas pela inflorescência (racemosa corimbiforme em C. neesiana e cimosa uniflora em C. cathartica). Chamaecrista neesiana possui distribuição em áreas de Cerrado e Campo rupestre, sob solo pedregoso. Coletada com flores em março e maio e frutos em março e dezembro.

12. Chamaecrista nictitans subsp. brachypoda (Benth.) H.S. Irwin \& Barneby, Mem. New York Bot. Gard. 35: 812. 1982.

Fig. 2f; 5b-c

Subarbusto ereto até $1,20 \mathrm{~m}$ alt.; ramos pubescentes, cilíndricos, não flexuosos, não ocultos 
pelas estípulas. Estípulas triangulares, $2-5 \mathrm{~mm}$ compr., pubescentes; nectários extraflorais 1-2, sésseis, localizados logo abaixo do primeiro par de folíolos ou na região mediana do pecíolo, oblongos ou orbiculares, pateliformes; folíolos 7-19 pares, oblongos, ápice acuminado, base assimétrica, 3-16 $\times 1-2 \mathrm{~mm}$, pubescentes em ambas as faces, venação pinada, margem repanda, nervura principal deslocada para a margem do pecíolo. Inflorescência supra-axilar, uniflora; pedicelo 2-3 $\mathrm{mm}$ compr., pubescente, adnato ao ramo; sépalas lanceoladas, 4-6 mm compr., acuminadas, internamente glabras, externamente pubescentes; pétalas externas 4 , obovadas a oblongas, $4-5 \mathrm{~mm}$ compr., pétala interna $36 \mathrm{~mm}$ compr., estames 10 , anteras glabras; ovário extremamente piloso. Legume linear, 28-37 $\times$ 3-4 mm, pubescente, cartáceo.

Material examinado: $18^{\circ} 07^{\prime} 2.6$ "S (aprox.), 4320'51.7'W (aprox.), III.2012, fl. e fr., M. Borba et al. 2 (OUPR).

Chamaecrista nictitans subsp. brachypoda é de fácil reconhecimento por apresentar a inflorescência supra-axilar e pedicelos adnatos aos ramos. Segundo Irwin \& Barneby (1982) são reconhecidas quatro subespécies distribuídas em 11 variedades. No PERP, ocorre em áreas de Cerrado e Campo rupestre. Coletada com flores e frutos em março.

13. Chamaecrista olesiphylla (Vogel) H.S. Irwin \& Barneby, Mem. New York Bot. Gard. 35: 670. 1982.

Figs. 2d; 5d

Subarbusto até $1 \mathrm{~m}$ alt., geralmente prostrado a decumbente; ramos pubescentes, cilíndricos, fractiflexos. Estípulas triangulares, agudas, base truncada, 3-7 mm compr., persistentes; pecíolo 6-9 mm compr., pubescente; nectário extrafloral 1, localizado abaixo do primeiro par de folíolos, pateliforme, orbicular, séssil; folíolos 7-14 pares, oblongos, ápice mucronado, base assimétrica, 11-14 × 3-5 mm, pubescentes em ambas as faces, margem inteira com tricomas, venação actinódroma. Inflorescência cimeira, axilar, uniflora; pedicelo 13-15 mm compr., pubescente; brácteas triangulares, pubescentes; sépalas ovadas a lanceoladas, pubescentes em ambas as faces, 11-15 mm compr.; pétalas externas 4, oblongas, atenuadas, $25 \times 6-9 \mathrm{~mm}$, pétala interna cuculada, $25 \mathrm{~mm}$ compr.; estames 10, anteras glabras; ovário densamente piloso. Legume linear, 27-36 $\times 4-5$ $\mathrm{mm}$, pubescente.

Material examinado: Trilha "Pinturas Rupestres", 8.XII.2013, fr., L.G.M. Vieira et al. 96 (OUPR); areal próximo a Cachoeira do Crioulo, $18^{\circ} 08^{\prime} 44.1^{\prime \prime}$, $43^{\circ} 22^{\prime} 09.8^{\prime \prime W}$, 24.III.2014, fl., A. Soldevila et al. 85 (OUPR); 19.IX.2012, fl. e fr., A.P. Fortuna-Perez et al. 1480 (OUPR); trilha da cachoeira Sempre Viva pelo rio sentido Forquilha, $18^{\circ} 08^{\prime} 32.7^{\prime \prime}$, $43^{\circ} 20^{\prime} 59.6^{\prime}$ 'W, 8.VI.2014, fl. e bt., A.P. Forturna-Perez et al. 1587 (OUPR); trilha roteiro "Pinturas rupestres", $18^{\circ} 05^{\prime} 25.3^{\prime}$ 'S, 4320'27.5”'W, 25.VIII.2014, fl. e fr., L.C. Zeferino et al. 55 (OUPR); topo da cachoeira do Crioulo, 24.VIII.2014, fl. e fr, L.C. Zeferino et al. 49 (OUPR).

Chamaecrista olesiphylla é de fácil distinção por possuir estípulas estreitamente triangulares, agudas e rígidas. Em ramos mais velhos as estípulas se tornam enegrecidas. Esta espécie foi encontrada em solo arenoso e áreas de Campo rupestre quartzítico e Cerrado. Coletada com flores em março, junho, agosto e setembro e frutos em agosto, setembro e dezembro.

14. Chamaecrista ramosa var. erythrocalyx (Benth.) H.S. Irwin \& Barneby, Mem. New York Bot. Gard. 35(2): 887. $1982 . \quad$ Figs. 6a-b

Subarbusto ereto, até $1,30 \mathrm{~m}$ alt., ramificado; ramos intermitentes cobertos por estípulas, pubérulos a glabrescente, não flexuosos. Estípulas ovais, lanceoladas, ápice agudo, base com prolongamentos em ambos os lados, 3-17 mm compr., caducas ou persistentes; pecíolo 2-7 mm compr., pubérulo a glabro, nectário extrafloral 1, peciolar, pateliforme, séssil; folíolos 2 pares, os distais maiores que os proximais, obovados, ápice arredondado, base assimétrica, os proximais 3-21 $\times 1-6 \mathrm{~mm}$, distais 5-25 × 1,5-6 mm, glabros a glabrescentes em ambas as faces; $3-5$ nervuras salientes em ambas as faces, venação acródroma. Inflorescência uniflora, axilar; pedicelo 15-23 $\mathrm{mm}$ compr.; bractéolas localizadas próximas ao ápice, ca. 3-5 mm compr., ovais, ápice acuminado; botões com ápice acuminado; sépalas ovadas, elípticas a lanceoladas, acuminadas, multiestriadas externamente, 2 externas $6-10 \mathrm{~mm}$ compr., 3 internas 10-17 mm compr.; pétalas externas 4, obovadas, 10-16 mm compr., interna cuculada, ca. 15-18 mm compr.; estames 10, anteras glabras; ovário estrigoso a glabro. Legume linear, 30-40 × 6-12 mm, reflexo, estrigoso a glabro.

Material examinado: Vau Bravo, $18^{\circ} 06^{\prime} 30.1^{\prime \prime}$, $43^{\circ} 19^{\prime} 53.5$ ”'W, 8.XII.2013, fl. e fr., L.G.M. Vieira et al. 75 (OUPR); Vargem da Estrela, 18 $07^{\circ} 46.6^{\prime \prime}$, $43^{\circ} 21^{\prime} 58.0^{\prime \prime} \mathrm{W}, 7 . X I I .2013$, fl. e fr., L.G.M. Vieira et al. 32 (OUPR); fr., L.C. Zeferino et al. 21 (OUPR); fl. e fr., L.C. Zeferino et al. 34 (OUPR); 7.XII.2013, fl. e fr., L.G.M. Vieira et al. 52 (OUPR); Vargem da Estrela, $18^{\circ} 07^{\prime} 46.6^{\prime \prime} \mathrm{S}, 43^{\circ} 21^{\prime} 58.0^{\prime}$ 'W, 7.XII.2013, fl. e fr., L.G.M. 
Vieira et al. 31 (OUPR); estrada próximo a Pinturas Rupestres, $18^{\circ} 05^{\prime} 29.4^{\prime \prime S}, 43^{\circ} 20 ’ 30.2^{\prime \prime} \mathrm{W}, 18$.XII.2013, fl. e fr., A. Soldevila et al. 14 (OUPR); Prainha, 18.XII.2013, fl. e fr., A. Soldevila et al. 27 (OUPR); próximo à placa das corredeiras, $18^{\circ} 05^{\prime} 22.8^{\prime}$ 'S, 4320'34.1'W, 29.X.2013, fl. e fr., L.C. Zeferino et al. 31 (OUPR); trilha para a Cachoeira do Crioulo, $18^{\circ} 08^{\prime} 09.5$ 'S, 4320'44.2”W, 27.X.2013, fl., L.C. Zeferino et al. 23 (OUPR); próximo à placa das corredeiras, $18^{\circ} 07^{\prime} 10.7^{\prime \prime} \mathrm{S}$, 43²0'35.2”'W, 28.X.2013, fl. e fr., L.C. Zeferino et al. 30 (OUPR); Vau Bravo, 1806’30.1”S, 43॰19'53.5”W, 8.XII.2013, fl. e fr., L.G.M. Vieira et al. 76 (OUPR);
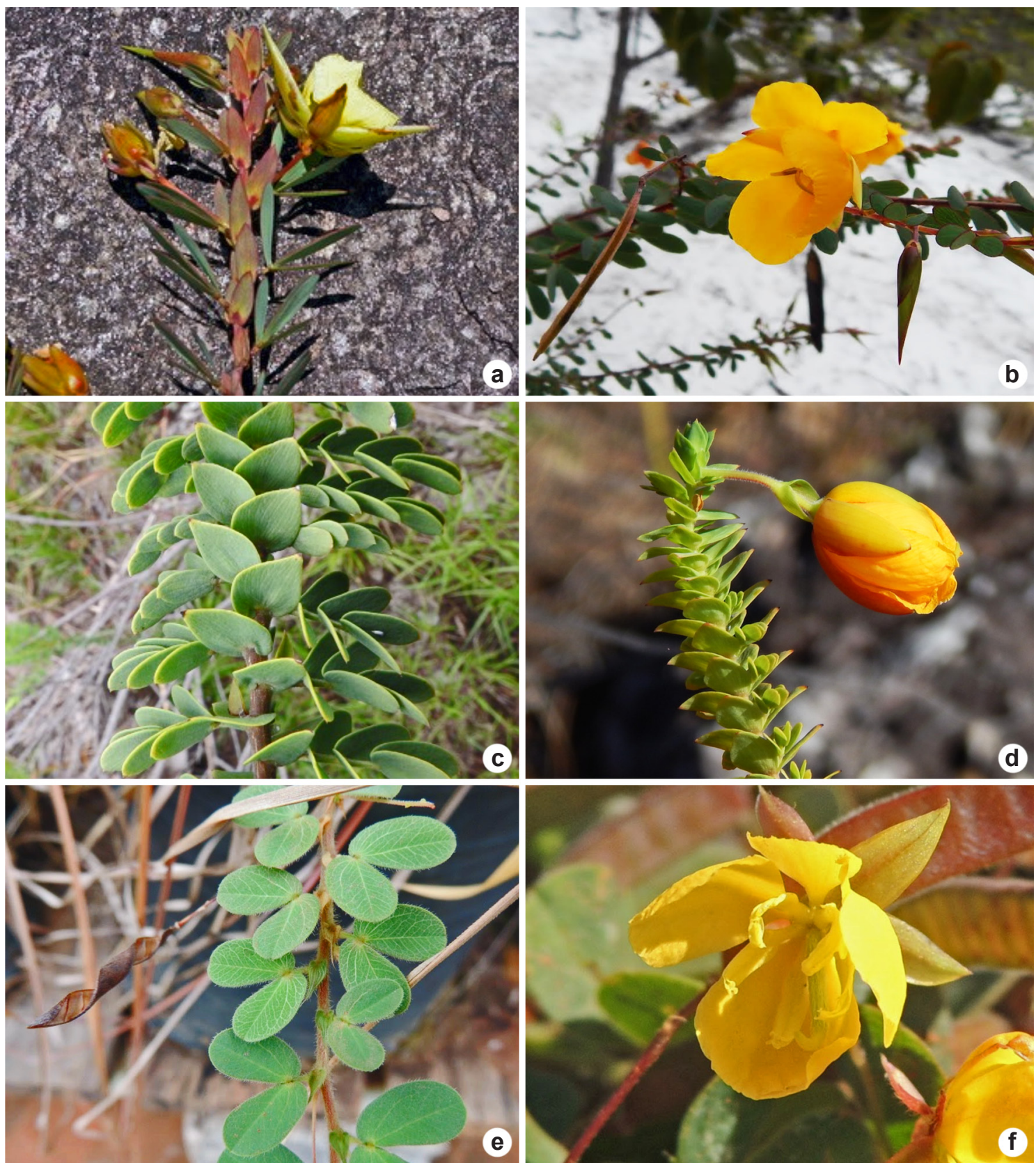

Figura 6 - a-b. Chamaecrista ramosa var. erythrocalyx - a. ramos ocultos pelas estípulas, folha tetrafoliolada; b. flor assimétrica. c-d. C. rotundata var. interstes - c. estípulas ovadas; d. ramo florido. e-f. C. rotundifolia-e. folha bifoliolada; f. flor. Fotos: Zeferino LC, Queiroz RT.

Figure 6-a-b. Chamaecrista ramosa var. erythrocalyx - a. stems hidden by stipules, tetrafoliolate leaf; b. assimetric flower. c-d. C.rotundata var. interstes - c. ovate stipule; d. flowery stem. e-f. C. rotundifolia - e. bifoliolate leaf; f. flower. Photos: Zeferino LC, Queiroz RT. 
1806’34.6”S, 4320'19.5”S, III.2012, fr., A.P. FortunaPerez et al. 1407 (OUPR).

Das seis variedades existentes para Chamaecrista ramosa, apenas C. ramosa var. erythrocalyx ocorre no PERP, sendo muito encontrada na região. Diferencia-se das outras espécies do Parque por apresentar estípulas caducas ou persistentes, ramos pubérulos a glabros, 2 pares de folíolos e inflorescência uniflora, axilar. Esta espécie foi encontrada em Campos rupestres com solos pedregosos e arenosos. Coletada com flores em março, agosto, outubro e dezembro, e frutos em agosto, outubro e dezembro.

15. Chamaecrista rotundata var. interstes H.S. Irwin \& Barneby, Mem. New York Bot. Gard. 35(2): 677. 1982.

Fig. 6c-d

Subarbusto até $1 \mathrm{~m}$ alt., ramos inteiramente cobertos por estípulas, pubérulos. Estípulas ovadas, ápice rotundo, 5-9 $\mathrm{mm}$ compr., persistentes; pecíolos 2-3 mm compr., pubescentes; nectário extrafloral 1, séssil; folíolos (2-)3 pares, oblongos ou elípticos, ápice mucronado, base assimétrica, 5-7 $\times 3-4 \mathrm{~mm}$, face adaxial e abaxial lisa, margem inteira, nervação actinódroma. Inflorescência uniflora, axilar; pedicelo 7-14 mm compr.; brácteolas $5 \mathrm{~mm}$ compr.; sépalas elípticas, 12-14 mm compr., acuminadas, externamente com tricomas, internamente glabras; pétalas externas 4, obovadas, $12-15 \times 7-10 \mathrm{~mm}$, pétala interna $21 \times 12 \mathrm{~mm}$; anteras glabras 10; ovário seríceo. Legume linear, 36-48 × 5-6 mm, velutino, ápice acuminado, coriáceo.

Material examinado: Vau Bravo, $18^{\circ} 06^{\prime} 30.1$ 'S, 4319'53.5"W, 8.XII.2013, fr., L.G.M. Vieira et al. 80 (OUPR); trilha para a cachoeira do Crioulo, $18^{\circ} 08^{\prime} 79.5^{\prime}$ 'S, $43^{\circ} 20^{\prime} 76.5^{\prime}$ 'W, 18.V.2012, fl. e fr., E.S. Cândido et al. 1041 (OUPR); próximo à placa de $6 \mathrm{~km}$ do restaurante F. dos Santos, 1809'12.7'S, 4319'01.7'W, 7.VI.2014, fl., I.F. Fantini et al. 6 (OUPR); próximo à "Vargem da Estrela", 1807'49.3"S, 43²2'43.1"W, 22.VIII.2014, fr., L.C. Zeferino et al. 41 (OUPR); trilha para o Poço do Veado, $18^{\circ} 06^{\prime} 36.7^{\prime}$ 'S, 4320'18.4'W, 21.VIII.2014, fl. e fr., L.C. Zeferino et al. 33 (OUPR).

Chamaecrista rotundata var. interstes pode ser reconhecida por possuir ramos inteiramente cobertos por estípulas ovadas. Outra característica marcante são as folhas com poucos pares de folíolos (2-3), sendo esses folíolos menores que as estípulas em comprimento e largura. Este táxon pode ser encontrado em áreas de Campo rupestre quartzítico e Cerrado.

Coletada com flores em maio, junho e agosto, e frutos em maio, agosto e dezembro.
16. Chamaecrista rotundifolia (Pers.) Greene, Pittonia 4: 31. 1899.

Fig. 6e-f

Subarbusto prostrado, até $40 \mathrm{~cm}$; ramos pilosos com tricomas glandulares esparsos e tricomas tectores, não flexuosos, não ocultos pelas estípulas. Estípulas ovadas, lanceoladas, ápice atenuado ou acuminado, base cordada, 4-16 mm compr., persistentes; pecíolo 3-6 mm compr., piloso com tricomas longos; nectários extraflorais ausentes; folíolos 1 par, obovados, ápice arredondado, base assimétrica, 3-24 × 2-19 $\mathrm{mm}$, glabros na face abaxial, pilosos na face adaxial, margem ciliada, venação actinódroma. Inflorescência 1-3 flores, axilar, pedúnculo 14$41 \mathrm{~mm}$ compr.; brácteas lanceoladas, 9-10 mm compr.; sépalas lanceoladas, 6-8 mm compr., internamente glabras, externamente pilosas com tricomas longos; pétalas externas 4 , obovadas, 6-7 $\times 3-5 \mathrm{~mm}$, pétala interna $7 \times 4 \mathrm{~mm}$; estames 5 , estaminódios 3 , anteras glabras; ovário viloso. Legume linear, 21-37 × 3-4 mm, levemente pubescente.

Material examinado: $20^{\circ} 23^{\prime} 46.6$ 'S, 4330'36.9'W, 26.I.2013, fl. e fr., L.C. Zeferino et al. 1 (OUPR); Capão das Candeias, $1^{\circ} 07^{\prime}$ '42.0'S, 4322'52.7'W, 7.XII.2013, fr., L.G.M. Vieira et al. 41 (OUPR); 18.V.2012, fr., E.S. Cândido et al. 1008 (OUPR); trilha entre o Vau Bravo e Vau das Éguas, 1806'13.3'S, 4319'45.7'W, 8.XII.2013, fl. e fr., L.G.M. Vieira et al. 83 (OUPR); estrada para o PERP em frente à Sapucaia, $18^{\circ} 03^{\prime} 14.4^{\prime}$ 'S, $43^{\circ} 22^{\prime} 24.8^{\prime \prime} \mathrm{W}, 29 . X .2013$, fl. e fr., L.C. Zeferino et al. 32 (OUPR).

Chamaecrista rotundifolia pode ser facilmente reconhecida pelo hábito subarbustivo prostrado, por um par de folíolos e pela ausência de nectário extrafloral. No PERP pode ser confundida com C. basifolia (ver comentário desta espécie). Ocorre em ambientes de Campo rupestre e Cerrado do PERP e em lugares perturbados como beira de estradas. Coletada com flores e frutos em janeiro, agosto, outubro e dezembro.

17. Chamaecrista setosa var. paucivenia (H.S. Irwin \& Barneby) H.S. Irwin \& Barneby, Mem. New York Bot. Gard. 35(2): 651. 1982.

Figs. 2i; 7a

Subarbusto ereto, 1-1,5 m alt., viscoso; ramos com tricomas híspidos, glandulares e estrelados. Estípulas 4-6 mm compr., filiformes; pecíolo 21-56 mm compr., pubescente, estrigoso, com presença de tricomas tectores e glandulares; setas 2-6 mm compr.; nectários extraflorais ausentes; folíolos 2 pares, oval-oblongos, coriáceos, ápice retuso, mucronado, base assimétrica, 17-84 $\times$ 

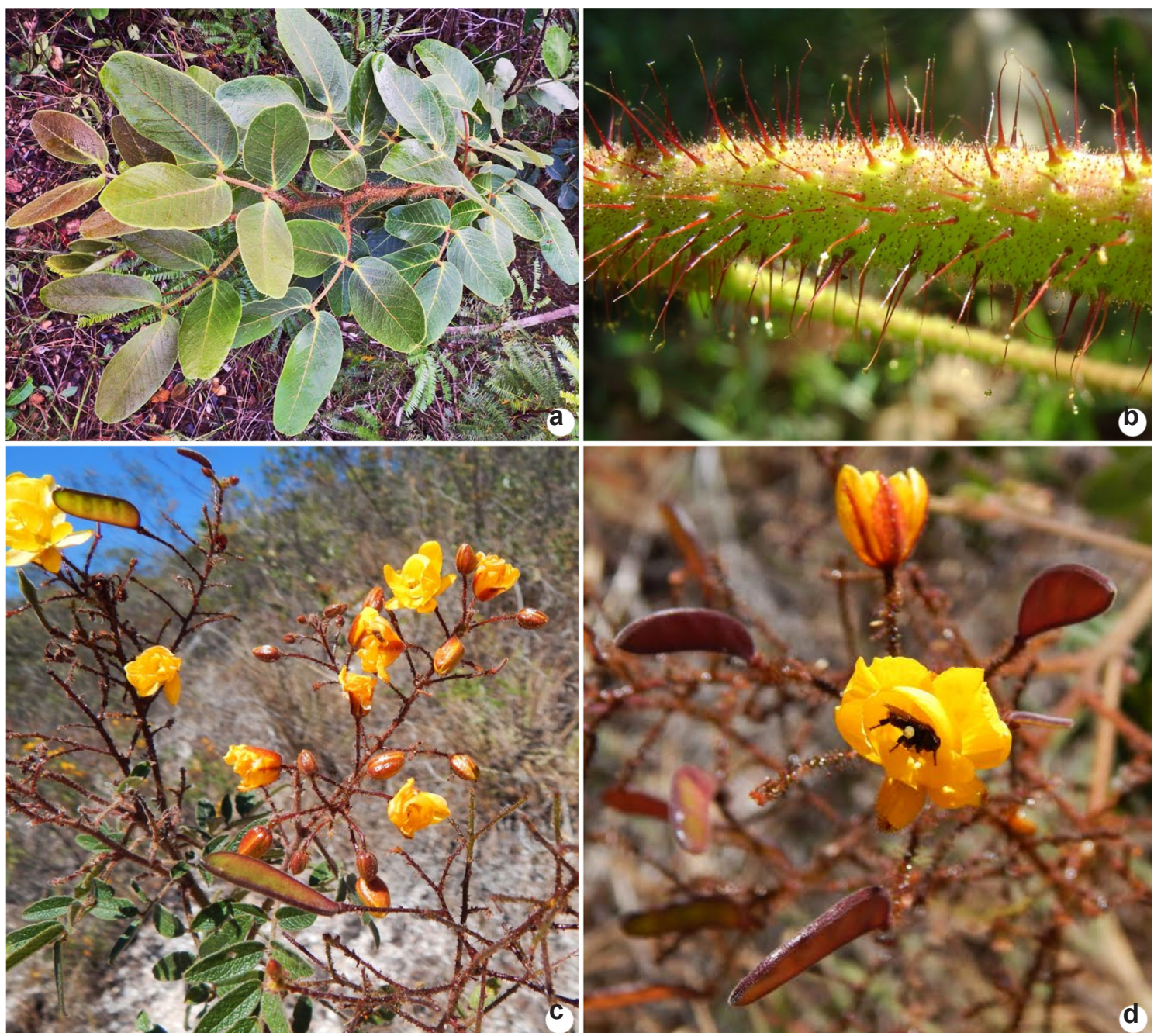

Figura 7 - a. Chamaecrista setosa - ramo prostrado, folha tetrafoliolada. b. C. stillifera-sépalas isomórficas c-d. C. ursina - c. inflorescência terminal; d. flores e frutos. Fotos: Zeferino LC, Fortuna-Perez AP, Cordoba AS, Queiroz RT. Figure 7 - a. Chamaecrista setosa - prostrate stem, tetrafoliolate leaf; b. C. stillifera - isomorphic sepals. c-d. C. ursina - c. terminal inflorescence; d. flowers and fruit. Photos: Zeferino LC, Fortuna-Perez AP, Cordoba AS, Queiroz RT.

14-37 mm, face abaxial com presença de tricomas glandulares estrelados e tricomas tectores apenas sobre as nervuras, face adaxial também coberta por tricomas tectores e estrelados, ambas as faces estrigosas, venação broquidródoma, margem inteira. Inflorescência racemo, axilar, 12-15 flores; pedicelo pubescente, $12-30 \mathrm{~mm}$ compr.; sépalas, elípticas, $18-19 \times 4-7 \mathrm{~mm}$ compr., tricomas tectores e glandulares na face adaxial; pétalas externas 4 , obovadas, $12-13 \times$ $8-10 \mathrm{~mm}$, pétala interna oboval, $10 \times 9 \mathrm{~mm}$; estames pubescentes, 10; ovário seríceo. Fruto não observado.

Material examinado: trilha para a cachoeira do Crioulo, 24.III.2014, fl., A. Soldevila et al. 88 (OUPR); trilha para a cachoeira do Crioulo, 18.V.2012, fl., E.S. Cândido et al. 1039 (OUPR); Vargem da Estrela,

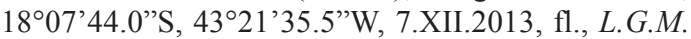
Vieira et al. 28 (OUPR).

Chamaecrista setosa possui três variedades e no PERP foi encontrada apenas a C. setosa var. paucivenia. Este táxon pode ser reconhecido por possuir ramos, pecíolo e eixo da inflorescência densamente indumentados com tricomas longos. Possui folhas com dois pares de folíolos que apresentam tricomas glandulares estrelados e tectores, estes, porém presentes apenas sob as nervuras. Ocorre no Cerrado e Campo rupestre dentro do PERP. Coletada com flores em marco, maio e dezembro. 
18. Chamaecrista stillifera (H.S. Irwin \& Barneby) H.S. Irwin \& Barneby, Mem. New York Bot. Gard. 35: 658. 1982.

Fig. 7b

Subarbusto até $1 \mathrm{~m}$ alt., ramos glabrescentes com tricomas glandulares, oblíquos. Estípulas triangular-lineares, 1-3 mm compr., caducas; pecíolos 14-22 mm compr., glabrescentes; nectários extraflorais ausentes; folíolos 2-3 pares, lanceolados, coriáceos, ápice atenuado, base assimétrica, 11-57 $\times 4-20 \mathrm{~mm}$, face adaxial lisa com tricomas glandulares esparsos, aspecto brilhoso, face abaxial lisa, algumas vezes pulverulenta, margem inteira, nervura broquidódroma. Inflorescência racemosa, terminal, uniflora; botões florais turbinados; pedicelo 25-34 mm compr.; sépalas elípticas, 14-20 mm compr., acuminadas, externamente com tricomas, internamente glabrescentes; pétalas externas 4, obovadas, 13-16 × 7-11 mm, pétala interna assimétrica, falcada, $17 \times 6 \mathrm{~mm}$; anteras glabras, 10 ; ovário amarelo com tricomas. Legume oblongo, 24 $32 \times 7-8 \mathrm{~mm}$, superfície lisa com aspecto brilhante, presença de tricomas glandulares, coriáceo.

Material examinado: trilha da cachoeira da Sempre Viva pelo rio sentido Forquilha, $18^{\circ} 08^{\prime} 32.7^{\prime}$ 'S, 4320'59.6”'W, 8.VI.2014, fl. e fr., A.P. Fortuna-Perez et al. 1588 (OUPR); trilha para Prainha, 23.III.2014, bot., A. Soldevila et al. 60 (OUPR).

Chamaecrista stillifera é de fácil identificação devido aos pares de folíolos extremamente lanceolados e coriáceos. São encontradas em solo arenoso e pedregoso de áreas de Campo rupestre e Cerrado. Coletada com flores e frutos em junho e com botões em março.

19. Chamaecrista ursina (Benth.) H.S. Irwin \& Barneby, Mem. New York Bot. Gard. 35: 650. 1982.

Fig. $7 \mathrm{c}-\mathrm{d}$

Subarbusto até $1,7 \mathrm{~m}$ alt., ramos extremamente pubescentes com muitos tricomas glandulares e tectores. Estípulas triangular-lineares, $2-8 \mathrm{~mm}$ compr., caducas; pecíolos 12-21 mm compr., densamente pubescentes; nectários extraflorais ausentes; folíolos 5-7 pares, geralmente elípticos, ápice obtuso a emarginado, mucronado, base assimétrica, $11-47 \times 5-14 \mathrm{~mm}$, face adaxial e abaxial densamente pubescentes com tricomas glandulares e tectores, margem inteira, ciliada, nervação reticulódroma. Inflorescência pleiocásio, 3-5-flora, terminal, botões florais ovais a obovados, ápice agudo, às vezes globoso com ápice apiculado; pedicelo 9-24 mm compr.; sépalas elípticas, 11$12 \mathrm{~mm}$ compr., acuminadas, externamente com tricomas, internamente glabrescentes; pétalas externas 4, obovadas, $12-18 \times 7-13 \mathrm{~mm}$, pétala interna $20 \times 11 \mathrm{~mm}$; anteras glabras; ovário piloso. Legume oblongo, 13-31 × 5-9 mm, levemente estrigoso, coriáceo.

Material examinado: trilha da cachoeira Sempre Viva pelo rio sentido Forquilha, $18^{\circ} 08^{\prime} 2.7^{\prime \prime} \mathrm{S}, 43^{\circ} 20^{\prime} 59.6^{\prime}$ 'W, 8.VI.2014, fl., A.P. Fortuna-Perez et al. 1590 (OUPR); beira da trilha para os banheiros, $18^{\circ} 07^{\prime} 52.4^{\prime \prime}$ 'S, $43^{\circ} 20^{\prime} 16.0^{\prime \prime} \mathrm{W}$, 24.III.2014, fr., A. Soldevila et al. 70 (OUPR); Mirante do Lageado, 18.V.2012, fl., E.S. Cândido et al. 1037 (OUPR); Mirante do Lageado, 18.V.2012, fl., E.S. Cândido et al.

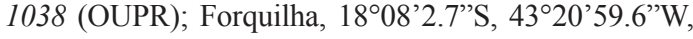
8.VI.2014, fl., I.F. Fantini et al. 13 (OUPR); início da trilha para cachoeira Sempre Viva, $18^{\circ} 08^{\prime} 13.7$ 'S, 4319'53.1”W, 7.VI.2014, fl., I.F. Fantini et al. 18 (OUPR); trilha secundária para cachoeira Sempre Viva, $18^{\circ} 08^{\prime} 10.2^{\prime \prime}$ 'S, 4321'27.9'W, 8.VI.2014, fl., I.F. Fantini et al. 21 (OUPR); antes da Rocha do Tatu próximo ao córrego da Lapa, 19.IX.2012, fl. e fr., L. Ferreira et al. 10 (OUPR); 8.XII.2013, fr., L.G.M. Vieira et al. 19 (OUPR); trilha para as cachoeiras, $18^{\circ} 07^{\prime} 22.2^{\prime \prime} \mathrm{S}, 43^{\circ} 20^{\prime} 34.8^{\prime \prime} \mathrm{W}$, 27.X.2013, fr., L.C. Zeferino et al. 22 (OUPR).

Chamaecrista ursina pode ser facilmente identificada por possuir ramos densamente pubescentes e folíolos com muitos tricomas glandulares e tectores por toda a superfície. Os tricomas localizados em ramos próximos às inflorescências liberam uma secreção glutinosa de cor alaranjada. São encontradas em áreas de Campo rupestre e em Cerrado do PERP de forma abundante. No parque pode ser confundida com C. astrochiton (ver comentário desta espécie). Coletada com flores em maio, junho e setembro, e frutos em março, setembro e outubro.

\section{Agradecimentos}

Os autores agradecem à FAPEMIG (processo APQ-02323-12) e ao CNPq (processo 457911/20131), o apoio financeiro a este trabalho que corresponde à Monografia de Bacharelado da primeira autora. Ao IEF, a licença concedida e a todos os funcionários do Parque Estadual do Rio Preto (PERP). Ao Herbário "Professor José Bandini" (OUPR), assim como à Universidade Federal de Ouro Preto (UFOP).

\section{Referências}

BFG - Brazil Flora Group (2015) Growing knowledge: an overview of seed plant diversity in Brazil. Rodriguésia 66: 1085-1113.

Camargo RA \& Miotto STS (2004) O gênero Chamaecrista Moench (Leguminosae - Caesalpinioideae) no Rio Grande do Sul. Iheringia 59:131-148.

Conceição AC (2000) O gênero Chamaecrista Moench (Leguminosae-Caesalpinioideae) em Catolés, Abaíra, Chapada Diamantina, Bahia, Brasil. Dissertação de 
Mestrado. Universidade Federal de Pernambuco, Recife. 143p.

Conceição AS, Giulietti AM \& Queiroz LP (2003) O gênero Chamaecrista Moench (LeguminosaeCaesalpinioideae) em Catolés, Abaíra, Chapada Diamantina, Bahia. Brasil. Sitientibus 3: 81-108

Dantas MM \& Silva MJ (2013) O gênero Chamaecrista (Leguminosae, Caesalpinioideae, Cassieae) no Parque Estadual da Serra Dourada, Goiás, Brasil. Rodriguésia 64: 581-595.

Herendeen PS (2000) Structural evolution in the Caesalpinioideae (Leguminosae). In: Herendeen PS \& Bruneae A. Advances in legume systematics 9. Royal Botanic Gardens, Kew. Pp. 45-64.

Hervencio P (1999) O gênero Chamaecrista seção Absus (Collad.) H.S. Irwin \& Barneby na Serra do Cipó, Minas Gerais, Brasil. Dissertação de Mestrado. Universidade de São Paulo, São Paulo. 148p.

IEF - Instituto Estadual de Florestas. Disponível em $<$ http:// www.ief.mg.gov.br>. Acesso em outubro 2014.

IPNI - The International Plant Names Index (2012) Disponível em $<$ http://www.ipni.org $>$. Acesso em 1 julho 2012.

Irwin HS \& Barneby RC (1977) Monographic studies in Cassia (Leguminosae Caesalpinioideae). IV. Supplementary notes on section Apoucouita Bentham. Brittonia 29: 277-290.

Irwin HS \& Barneby RC (1978) Monographic studies In: Cassia (Leguminosae-Caesalpinioideae) III. Sections Absus and Grimaldia. Memoirs of the New York Botanical Garden 30: 1-300.

Irwin HS \& Barneby RC (1981) Cassieae. In: Polhill RM \& Raven PH. Advances in legume systematics part I. Royal Botanic Gardens, Kew. Pp. 97-106.

Irwin HS \& Barneby RC (1982) The American Cassinae: a synoptical revision of Leguminosae Tribe Cassieae subtribe Cassinae in the New World. Memoirs of the New York Botanical Garden 35: 1-918.

Kew Herbarium Catalogue (2017) Disponível em $<$ http:// apps.kew.org/herbcat/navigator.do $>$. Acesso em 15 outubro 2017.

Lewis GP, Schrire B, Mackinder B \& Lock M (eds.) (2005) Legumes of the world. Royal Botanic Gardens, Kew. $577 \mathrm{p}$.

LPWG - Legume Phylogeny Working Group (2013) Legume phylogeny and classification in the $21^{\text {st }}$ century: progress, prospects and lessons for other species-rich clades. Taxon 62: 217-248.

LPWG - Legume Phylogeny Working Group (2017) A new subfamily classification of the Leguminosae based on a taxonomically comprehensive phylogeny. Taxon 66: 44-77.
Neves SC, Abreu PAA \& Fraga LMS (2005) Fisiografia. In: Silva AC, Pedreira LCVSF \& Abreu PAA (eds.) Serra do Espinhaço Meridional: paisagens e ambientes. Editora O Lutador. Belo Horizonte. Pp. 47-58.

Queiroz RT \& Loiola MIB (2009)O gênero Chamaecrista Moench (Caesalpinioideae) em áreas do entorno do Parque Estadual das Dunas de Natal, Rio Grande do Norte, Brasil. Hoehnea 36: 725-736.

Rando JG (2009) Chamaecrista seções Apoucouita, Chamaecrista e Xerocalyx na Serra do Cipó, Minas Gerais. Dissertação de Mestrado. Universidade de São Paulo, São Paulo. 107p.

Rando JG, Hervencio P, Souza VC, Giulietti AM \& Pirani JR (2013) Flora da Serra do Cipó, Minas Gerais: Leguminosae- "Caesalpinioideae". Boletim de Botânica da Universidade de São Paulo 13: 141-198.

Rodrigues RS, Flores AS, Miotto STS \& Baptista LRM (2005) O gênero Senna (Leguminosae, Caesalpinioideae) no Rio Grande do Sul, Brasil. Acta Botanica Brasilica 19: 1-16.

Scalon VR (2003) Flora do Distrito Federal, Brasil: Chamaecrista Moench Seção Absus (Collad.) H. S. Irwin \& Barneby (Caesalpiniaceae). Dissertação de Mestrado. Universidade de São Paulo, São Paulo. Pp. 83.

Souza VC \& Bortoluzzi RLC (2012) Chamaecrista. In: Forzza RC et al. (eds.) Lista das espécies da flora do Brasil. Jardim Botânico do Rio de Janeiro. Disponível em <http://floradobrasil.jbrj.gov.br/2012/ FB022876>. Acesso em agosto 2014.

Souza AO \& Silva MJ (2015) Estudo taxonômico do gênero Chamaecrista Moench. (Caesalpinioideae, Leguminosae) na Floresta Nacional de Silvânia, Goiás, Brasil. Iheringia 70: 73-88.

The New York Botanical Garden (2017) Disponível em $<$ https://www.nybg.org > Acesso em 15 outubro 2017.

The International Plant Names Index. Disponível em $<$ http://www.ipni.org > . Acesso em 15 outubro 2017.

UNESCO - Organização das Nações Unidas para a Educação a Ciência e a Cultura (2018) Reserva da Biosfera da Serra do Espinhaço. Disponível em <http://whc.unesco.org/>. Acesso em fevereiro 2018.

Versieux LM, Louzada RB, Vianna PL, Mota N \& Wanderley MGL (2010) An illustrated checklist of Bromeliaceae from Parque Estadual do Rio Preto, Minas Gerais, Brazil, with notes on phytogeography and one new species of Cryptanthus. Phytotaxa 10: $1-16$. 